\title{
Information Content of Analysts' Stock Ratings and Earnings Forecasts in the Presence of Management Earnings Forecasts*
}

\author{
Koji $\mathrm{OTA}^{\dagger}$ \\ Faculty of Commerce \\ KANSAI UNIVERSITY
}

\begin{abstract}
This paper evaluates the informativeness of analysts' ratings and earnings forecast information contained in analyst reports beyond what is publicly provided by management earnings forecasts. Using only analyst reports that have been released practically simultaneously with management forecasts, I find that both analysts' ratings and earnings forecasts have incremental information content conditional on management forecasts. Further analysis also reveals that analysts' earnings forecasts are significantly more accurate than concurrently-announced management earnings forecasts. Overall, the findings in this paper present strong evidence that analysts offer informational value to the market beyond information that is provided by company management.
\end{abstract}

JEL Classification: G14; D82; G24; M41

Key Words: Analysts' Roles in Financial Markets; Analysts' Stock Ratings; Analysts'

Earnings Forecasts; Management Earnings Forecasts

\section{Introduction}

Analyst reports provided by equity analysts are commonly used in the major stock markets of the world. Although the history of the so-called Western-style analyst reports in Japan is relatively short, they have been available since 1993 when Nomura Research Institute began publishing them. Numerous other stock brokerage firms soon followed suit. As of September 2007, 36 brokerage firms own equity research divisions or research institutes in Japan, with over 800 equity analysts belonging

\footnotetext{
* I appreciate financial supports from JSPS KAKENHI (Grant Number 23530391), the Kansai University Research Grants (Grantin-Aid for Encouragement of Scientists in 2011), and Ishii Memorial Securities Research Promotion Foundation (Grant-in-Aid for Research 22-04).

† Corresponding Author. Address Kansai University, 3-3-35 Yamatecho, Suita, Osaka 5648680, JAPAN.

Telephone+81(6)6368-1348 E-mail koji_ota@nifty.ne.jp
}

Received April 26, 2012; accepted July 4, 2012 
to these firms (Analyst Directory 2007; Nikkei Research Inc.). Most global investment banks, including Goldman Sachs, JP Morgan Chase, and Credit Suisse are among these firms.

Analyst reports are the final products of a process involving the collection, evaluation, and dissemination of information related to firms' future prospects, and those published in Japan are comparable to those in other countries. ${ }^{1}$ However, there is one unique feature of the analyst reports published in Japan that is not found in other countries: they include information on current management earnings forecasts along with analysts' earnings forecasts. This is because listed firms in Japan are required to provide forecasts of next year's earnings under the disclosure guidelines prescribed by Japanese stock exchanges; therefore, management forecast information is publicly available. This practice dates to 1974, when the Tokyo Stock Exchange sent a letter to listed firms requesting the disclosure of forecasts of key accounting information. After some changes in the disclosure guidelines, Japanese corporate managers are now required to provide annual forecasts of next year's sales, operating profit, recurring profit, net income, and dividends at quarterly and annual earnings announcements. In addition to periodic disclosure at earnings announcements, Japanese managers are also required to announce revised forecasts immediately when there is a significant change in previously published forecasts (e.g., $\pm 10 \%$ of a sales forecast, $\pm 30 \%$ of an earnings forecast, any change in a dividends forecast). This unique feature of analyst reports published in Japan motivated me to undertake this study.

Security analyst reports have been the subject of extensive empirical study over the past three decades. Many of these studies have investigated the stock market's reaction to the release of information contained in analyst reports using a short event window; these are often called information content studies. However, most information content studies on analyst reports assume that the reports provide new information to the market and are not concurrent with other public releases. If this assumption does not hold, there is a possibility that analysts are merely publicizing or reiterating information that is already public. This possibility is not well considered in the current literature (Asquith, Mikhail, and Au, 2005).

This paper investigates the informativeness of analysts' ratings and earnings forecasts conditional on the information contained in management earnings forecasts. I use 2,277 analyst reports publicized for the two-year period from July 2005 through June 2007 about 399 firms. I first replicate previous studies and find that both analysts' ratings and earnings forecast revisions provide independent information to the stock market. Then, I examine the timing of the publication of analyst reports relative to the announcement of management earnings forecasts. Investigating the timing of the release of analyst reports helps understand the value that analysts bring to the market. First, analysts' value may lie in their ability to interpret publicly available information through their expertise. Second, analysts' service may lie in their ability to collect and process a wide variety of information through independent research (Park and Pincus, 2000; Ivković and Jegadeesh, 2004). While analysts' roles as collectors of new information are well documented in the literature, their roles as interpreters of public information have not been thoroughly explored. Corporate insiders' views of future earnings are probably one of the most important sources of public information. Thus, investigating the informativeness of information contained in analyst reports after controlling for the

\footnotetext{
${ }^{1}$ Foreign securities firms operating in Japan appear to have a standard format for the report, and therefore their analyst reports are very similar to those used in other countries. On the other hand, analyst reports publicized by domestic securities firms are slightly different from those issued by foreign securities firms. Domestic brokerage firms usually employ a five-category system for rating stocks (strong buy, buy, hold, sell, and strong sell) and do not issue target prices, while foreign brokerage firms have a three-category system for rating stocks (buy, hold, and sell) and publicize target prices.
} 
impact of management forecasts will help shed light on whether analysts possess valuable expertise to interpret public information.

After examining the timing of the publication of analyst reports, I find that over half of the analyst reports are issued on the day after the announcement of management earnings forecasts. These analyst reports are released almost simultaneously with management forecasts because the announcement of management forecasts usually takes place after the market closes, and analyst reports are disseminated to clients before the market opens the next day. Thereafter, I investigate the informativeness of analysts' ratings and earnings forecasts on the subsample of concurrently released analyst reports, and find that both analysts' ratings and earnings forecasts have incremental information content beyond information provided by management earnings forecasts. Controlling for the impact of actual earnings surprises does not alter the results. These findings suggest that the stock market considers the information contained in analyst reports more credible than that in management forecasts.

In order to gain insights into the market's reliance on analysts' forecasts, I examine the ex post forecast accuracy of management earnings forecasts and concurrently released analysts' earnings forecasts. The results reveal that analysts' forecasts are significantly more accurate than management forecasts. This may offer a clue to why the market relies more on analysts' outlooks than corporate managers' views of future earnings. Security analysts appear to possess expertise to process public information and supply the market with new analysis and assessment on a company's future performance.

The remainder of this paper is organized in the following manner. The next section summarizes prior research. Section 3 describes the data and the sample. Section 4 discusses the empirical results. Section 5 provides the results of a battery of sensitivity tests. The last section presents the conclusion.

\section{Prior Research}

Early research on analyst reports investigates the information content of analysts' stock ratings and earnings forecasts separately. For example, Elton, Gruber, and Grossman (1986) examine the market reaction to analysts' rating changes using monthly returns, and find that upgrades to strong buy earn an average abnormal return of $1.91 \%$, while downgrades to strong sell produce an average abnormal return of $-0.38 \%$ in the month of rating changes. Womack (1996) examines not only stock price reactions but also volume reactions to stock rating changes to and from the most extreme buy and sell categories. He finds that upgrades to the buy rating and downgrades to the sell rating earn size-adjusted returns of $3.0 \%$ and $-4.7 \%$, respectively, and generate $190 \%$ and $300 \%$ of normal volume, respectively, in the three-day event period surrounding the release of rating changes. Other studies investigating changes in analysts' ratings also find positive associations between abnormal returns and the direction of the rating change (Barber, Lehavy, McNichols, and Trueman, 2001; Ivković and Jegadeesh, 2004).

The information content of analysts' earnings forecasts has also been extensively investigated. Abdel-khalik and Ajinkya (1982) examine the impact of 288 earnings forecast revisions by Merrill Lynch analysts on stock prices for the 1977-78 period and find significant abnormal returns during the publication week of the revisions. Studies using larger sample sizes also document evidence consistent with analysts' earnings forecast revisions having information content (Lys and Sohn, 1990; Stickel, 1991).

More recent research has simultaneously examined the information content of analysts' ratings, 
earnings forecasts, and other elements in the reports. For example, Francis and Soffer (1997) examine the relative informativeness of analysts' ratings and earnings forecast revisions and find that analysts' rating changes and earnings forecast revisions both affect stock prices. Stickel (1995) also investigates the information content of analysts' ratings and earnings forecast revisions using almost 17,000 observations and obtain results consistent with the Francis and Soffer study. He also finds that the magnitude of the recommendation revision, reputation of the analyst, size of the brokerage house, and size of the sample firm all influence stock prices. Brav and Lehavy (2003) extend Francis and Soffer's work by incorporating target prices as a source of information. Their evidence indicates that target price revisions are informative and provide significant incremental information over and above that contained in analysts' stock ratings and earnings forecast revisions. Moreover, Asquith et al. (2005) consider the written content of a report in conjunction with the three summary measures: analysts' ratings, earnings forecasts, and target prices. After a thorough investigation of 1,126 analyst reports, they find that the strength of analysts' arguments provide significant information to the market beyond the three summary variables.

Thus, the information content of analyst reports has been widely investigated. However, these information content studies assume that the publication of analyst reports does not occur with other public releases. If this is not the case, there is a possibility that the observed market reaction is triggered by the information in public releases and not by that in analyst reports. In order to deal with this concurrent event problem, many studies rerun the analysis in the robustness tests on the subsample of observations that occur independently (Francis and Soffer, 1997; Brav and Lehavy, 2003; Asquith et al., 2005). In this paper, instead of circumventing the problem of simultaneous public announcements by using a subsample, I directly control for the impact of public releases and examine the incremental informativeness of analyst reports.

My work also relates to a stream of research that investigates the value that analysts bring to the market. Ivković and Jegadeesh (2004) document that the information content of analysts' rating changes and earnings forecast revisions is the weakest during the week after earnings announcement and increases through the final week before the next earnings announcement. On the basis of this finding, they conjecture that the value of analysts' stock ratings and earnings forecasts stems more from their independent collection of information than from their interpretation of public information. However, they exclude from their analysis the analysts' rating changes and earnings forecast revisions that occur around the earnings announcement date, which accounts for approximately $25 \%$ of the entire sample, citing difficulty in disentangling the price reaction. Asquith et al. (2005) also find that 53\% of the 1,126 analyst reports examined are published around the dates of other public releases, particularly earnings announcements. They analyze these reports and obtain statistically weaker but significant results supporting the informativeness of analyst reports. On the basis of the results obtained, Asquith et al. surmise that analysts have a role in interpreting other public releases. However, since they did not directly control for the impact of other simultaneous announcements, they could not clearly determine whether the market reaction was triggered by information from analyst reports or from concurrent public releases. Thus, they suggest that future studies on analyst reports should address the question of whether these analyst reports with other information releases contain new or merely interpretive information. In this study, I focus on the analyst reports that are contemporaneous with one of the most important releases of public information to the market - earnings guidance provided by management-in order to investigate whether analysts add value to the market beyond what is publicly disseminated by corporate managers. 


\section{Sample and Data}

In this study, I examined 2,405 analyst reports provided by one of the three leading brokerage firms in Japan for the two-year period from July 2005 through June 2007. Other data necessary to carry out the empirical tests in the following sections are collected from NEEDS-FinancialQUEST, a commercial database provided by Nikkei Media Marketing Inc., and Kaisha Shikihou (Japan Company Handbook), a quarterly publication on listed firms in Japan issued by Toyo Keizai Inc.

The analyst reports cover 442 firms and are written by 52 sell-side analysts. Of the 2,405 analyst reports, 127 are initiations of coverage and one is a stoppage of coverage, and these are omitted from the sample. This leads to a final sample of 2,277 analyst reports for 399 firms written by 51 sell-side analysts. The number of reports per analyst varies from 1 to 167 , with a mean (median) of 48.9 (26.0) reports. ${ }^{2}$ The number of reports per sample firm also varies from 1 to 18 , with a mean (median) of 5.7 (6.0) reports.

In order to identify the characteristics of firms that analysts follow, the stock trading markets on which the sample firms are listed are presented in Panel A of Table 1. The far-right column of Panel A shows the breakdown of all listed firms as of June 2007 for referrence purposes. Of the 399 sample firms, 349 (87.5\%) are listed on the first section of the Tokyo Stock Exchange (TSE), while only 1,734 (44.0\%) of all listed firms are traded on the first section of the TSE. The first section of the TSE comprises blue-chip companies in Japan and is by far Japan's largest stock trading market, accounting for over $90 \%$ of the nation's stock trading (93.3\% of the trading volume and $92.5 \%$ of the trading value in 2007). Thus, the high concentration of sample firms on the first section of the TSE clearly indicates the tendency for analysts to cover large firms.

Table 1: Sample Firm Characteristics

\begin{tabular}{|c|c|c|c|c|}
\hline \multicolumn{5}{|l|}{ Panel A: Stock Exchange Market } \\
\hline \multirow[b]{2}{*}{ Stock Exchanges in Japan } & \multicolumn{2}{|c|}{ Sample firms } & \multicolumn{2}{|c|}{ All listed firms } \\
\hline & $N$ & $\%$ & $N$ & $\%$ \\
\hline Tokyo Stock Exchange 1st section & 349 & $87.5 \%$ & 1,734 & $44.0 \%$ \\
\hline Tokyo Stock Exchange 2nd section & 10 & $2.5 \%$ & 483 & $12.2 \%$ \\
\hline Osaka Securities Exchange 1st section & 0 & $0.0 \%$ & 35 & $0.9 \%$ \\
\hline Osaka Securities Exchange 2nd section & 3 & $0.8 \%$ & 211 & $5.4 \%$ \\
\hline Nagoya Stock Exchange 1st section & 0 & $0.0 \%$ & 8 & $0.2 \%$ \\
\hline Nagoya Stock Exchange 2nd section & 0 & $0.0 \%$ & 105 & $2.7 \%$ \\
\hline Fukuoka Stock Exchange & 0 & $0.0 \%$ & 40 & $1.0 \%$ \\
\hline Sapporo Securities Exchange & 0 & $0.0 \%$ & 23 & $0.6 \%$ \\
\hline JASDAQ & 30 & $7.5 \%$ & 955 & $24.2 \%$ \\
\hline Mothers of Tokyo Stock Exchange & 5 & $1.3 \%$ & 191 & $4.8 \%$ \\
\hline Hercules of Osaka Securities Exchange & 2 & $0.5 \%$ & 158 & $4.0 \%$ \\
\hline Total & 399 & $100.0 \%$ & 3,943 & $100.0 \%$ \\
\hline
\end{tabular}

(Continued)

${ }^{2}$ When analyst reports are written by multiple analysts, they are counted multiple times. 


\begin{tabular}{|c|c|c|c|c|}
\hline \multicolumn{5}{|l|}{ Panel B: Industry } \\
\hline \multirow{2}{*}{$\begin{array}{c}33 \text { sectors designated by Securities Identification } \\
\text { Code Committee (SICC) }\end{array}$} & \multicolumn{2}{|c|}{ Sample firms } & \multicolumn{2}{|c|}{ All listed firms } \\
\hline & $N$ & $\%$ & $N$ & $\%$ \\
\hline Fishery, Agriculture \& Forestry & 0 & $0.0 \%$ & 11 & $0.3 \%$ \\
\hline Mining & 2 & $0.5 \%$ & 7 & $0.2 \%$ \\
\hline Construction & 20 & $5.0 \%$ & 216 & $5.5 \%$ \\
\hline Foods & 0 & $0.0 \%$ & 153 & $3.9 \%$ \\
\hline Textiles \& Apparels & 1 & $0.3 \%$ & 81 & $2.1 \%$ \\
\hline Pulp \& Paper & 4 & $1.0 \%$ & 28 & $0.7 \%$ \\
\hline Chemicals & 38 & $9.5 \%$ & 219 & $5.6 \%$ \\
\hline Pharmaceuticals & 18 & $4.5 \%$ & 52 & $1.3 \%$ \\
\hline Oil \& Coal Products & 0 & $0.0 \%$ & 14 & $0.4 \%$ \\
\hline Rubber Products & 4 & $1.0 \%$ & 21 & $0.5 \%$ \\
\hline Glass \& Ceramic Products & 11 & $2.8 \%$ & 73 & $1.9 \%$ \\
\hline Iron \& Steel & 7 & $1.8 \%$ & 57 & $1.4 \%$ \\
\hline Nonferrous Metals & 8 & $2.0 \%$ & 43 & $1.1 \%$ \\
\hline Metal Products & 8 & $2.0 \%$ & 100 & $2.5 \%$ \\
\hline Machinery & 28 & $7.0 \%$ & 252 & $6.4 \%$ \\
\hline Electric Appliances & 57 & $14.3 \%$ & 313 & $7.9 \%$ \\
\hline Transportation Equipment & 21 & $5.3 \%$ & 107 & $2.7 \%$ \\
\hline Precision Instruments & 8 & $2.0 \%$ & 53 & $1.3 \%$ \\
\hline Other Products & 17 & $4.3 \%$ & 117 & $3.0 \%$ \\
\hline Electric Power \& Gas & 5 & $1.3 \%$ & 25 & $0.6 \%$ \\
\hline Land Transportation & 9 & $2.3 \%$ & 66 & $1.7 \%$ \\
\hline Marine Transportation & 3 & $0.8 \%$ & 18 & $0.5 \%$ \\
\hline Air Transportation & 0 & $0.0 \%$ & 6 & $0.2 \%$ \\
\hline Warehousing \& Harbor Transportation Services & 0 & $0.0 \%$ & 44 & $1.1 \%$ \\
\hline Information \& Communication & 0 & $0.0 \%$ & 364 & $9.2 \%$ \\
\hline Wholesale Trade & 18 & $4.5 \%$ & 393 & $10.0 \%$ \\
\hline Retail Trade & 49 & $12.3 \%$ & 393 & $10.0 \%$ \\
\hline Banks & 0 & $0.0 \%$ & 98 & $2.5 \%$ \\
\hline Securities \& Commodity Futures & 0 & $0.0 \%$ & 40 & $1.0 \%$ \\
\hline Insurance & 0 & $0.0 \%$ & 11 & $0.3 \%$ \\
\hline Other Financing Business & 10 & $2.5 \%$ & 58 & $1.5 \%$ \\
\hline Real Estate & 18 & $4.5 \%$ & 135 & $3.4 \%$ \\
\hline Services & 35 & $8.8 \%$ & 375 & $9.5 \%$ \\
\hline Total & 399 & $100.0 \%$ & 3,943 & $100.0 \%$ \\
\hline
\end{tabular}

Note: This table presents a summary of sample firm characteristics. 399 firms that are covered by analyst reports in this study are referred to as sample firms in the table. The breakdown of all listed firms, 3,943 firms as of June 2007, by stock exchange market and industry is shown for reference purposes in the far-right column. 
Table 2: Matrix of Changes in Analysts' Stock Ratings

\begin{tabular}{|c|c|c|c|c|c|c|}
\hline \multirow[b]{2}{*}{ Old Rating } & \multicolumn{6}{|c|}{ New Rating } \\
\hline & Strong Buy & Buy & Hold & Sell & Strong Sell & Total \\
\hline Strong Buy & $198^{c}$ & $21^{\mathrm{b}}$ & $14^{b}$ & $0^{\mathrm{b}}$ & $0^{\mathrm{b}}$ & 233 \\
\hline Buy & $15^{\mathrm{a}}$ & $753^{c}$ & $82^{\mathrm{b}}$ & $2^{\mathrm{b}}$ & $0^{\mathrm{b}}$ & 852 \\
\hline Hold & $2^{a}$ & $61^{a}$ & $1,002^{\mathrm{c}}$ & $27^{\mathrm{b}}$ & $0^{\mathrm{b}}$ & 1,092 \\
\hline Sell & $0^{\mathrm{a}}$ & $1^{\mathrm{a}}$ & $22^{\mathrm{a}}$ & $77^{\mathrm{c}}$ & $0^{\mathrm{b}}$ & 100 \\
\hline Strong Sell & $0^{\mathrm{a}}$ & $0^{\mathrm{a}}$ & $0^{\mathrm{a}}$ & $0^{\mathrm{a}}$ & $0^{c}$ & 0 \\
\hline Total & 215 & 836 & 1,120 & 106 & 0 & 2,277 \\
\hline$\%$ & $9.4 \%$ & $36.7 \%$ & $49.2 \%$ & $4.7 \%$ & 0 & $100 \%$ \\
\hline
\end{tabular}

Note: This table shows the matrix of changes in analysts' stock ratings. There are 101 upgrades (a), 146 downgrades (b), and 1,980 reiterations (c).

The industry classification of the sample firms is also shown in Panel B along with the breakdown of all listed firms. Sample firms in Pharmaceuticals, Electric Appliances, and Transportation Equipment have ratios almost twice as high as those of all listed firms. As an export-oriented country, many household-name companies in Japan, such as Toyota, Honda, Sony, Panasonic, and Takeda Pharmaceutical, belong to these industries. In addition, 131 of the 399 sample firms are used to calculate Japan's benchmark Nikkei 225 stock index. Taken together, the sample firms that analysts follow tend to be large, well-known blue-chip companies in Japan.

The analyst reports in this study use a five-category system to rate stocks (strong buy, buy, hold, sell, and strong sell). Table 2 presents the matrix of 2,277 changes in analysts' ratings. The bottom row of the table shows that $9.4 \%$ of current analysts' ratings are strong buy, $36.7 \%$ are buy, $49.2 \%$ are hold, $4.7 \%$ are sell, and none of the analysts' ratings is strong sell. This finding is consistent with many other studies. Analysts appear to be reluctant to issue sell or strong sell ratings. Further, Table 2 also shows that there are 101 upgrades, 146 downgrades, and 1,980 reiterations. It appears that analysts are also hesitant to change analysts' ratings. In the following tests, I combine hold and sell ratings into one category and convert the five-category system into a three-category system (strong buy, buy, and hold/sell). ${ }^{3}$

In addition to stock ratings, analysts also provide forecasts of key accounting figures for one or more future years. The key accounting figures include sales, operating profit, recurring profit, net income, EPS, CFPS, and dividends per share. In the following analysis, I use only sales, operating profit, recurring profit, and net income.

Table 3 summarizes the frequency of sales and earnings forecast revisions as well as forecast horizons. Forecast horizons vary from one-year ahead to three-years ahead. The one-year-ahead forecast is defined as the earliest year for which actual earnings had not been announced by the sample firm. Of the 2,277 analyst reports examined, 2,053 reports provide one-year-ahead forecasts, 1,977 reports provide two-year-ahead forecasts, and only 596 reports supply three-year-ahead forecasts. I do not calculate sales and earnings forecast revisions from two successive in time reports because occasionally analysts do not write reports on the same firm for months. Therefore, when previous sales and earnings forecasts are not

\footnotetext{
3 This treatment has been commonly used in other studies as well. For example, Francis and Soffer (1997) treat strong buy as buy and strong sell as sell, and Stickel (1995), using only changes in analysts' ratings, also regards hold as sell.
} 
Table 3: Analysts' Sales and Earnings Forecasts

\begin{tabular}{|c|c|c|c|c|c|c|c|}
\hline \multirow{2}{*}{$\begin{array}{l}\text { Forecasted } \\
\text { Item }\end{array}$} & \multirow{2}{*}{ Revisions } & \multicolumn{2}{|c|}{ One-year-ahead } & \multicolumn{2}{|c|}{ Two-year-ahead } & \multicolumn{2}{|c|}{ Three-year-ahead } \\
\hline & & $N$ & $\%$ & $N$ & $\%$ & $N$ & $\%$ \\
\hline \multirow{4}{*}{ Sales } & Upward & 995 & $48.5 \%$ & 937 & $47.4 \%$ & 249 & $41.8 \%$ \\
\hline & Unchanged & 622 & $30.3 \%$ & 630 & $31.9 \%$ & 250 & $41.9 \%$ \\
\hline & Downward & 436 & $21.2 \%$ & 410 & $20.7 \%$ & 97 & $16.3 \%$ \\
\hline & Total & 2,053 & $100.0 \%$ & 1,977 & $100.0 \%$ & 596 & $100.0 \%$ \\
\hline \multirow{4}{*}{$\begin{array}{l}\text { Operating } \\
\text { Profit }\end{array}$} & Upward & 739 & $36.0 \%$ & 727 & $36.8 \%$ & 229 & $38.4 \%$ \\
\hline & Unchanged & 662 & $32.2 \%$ & 638 & $32.3 \%$ & 224 & $37.6 \%$ \\
\hline & Downward & 652 & $31.8 \%$ & 612 & $31.0 \%$ & 143 & $24.0 \%$ \\
\hline & Total & 2,053 & $100.0 \%$ & 1,977 & $100.0 \%$ & 596 & $100.0 \%$ \\
\hline \multirow{4}{*}{$\begin{array}{l}\text { Recurring } \\
\text { Profit }\end{array}$} & Upward & 793 & $38.6 \%$ & 773 & $39.1 \%$ & 238 & $39.9 \%$ \\
\hline & Unchanged & 627 & $30.5 \%$ & 598 & $30.2 \%$ & 217 & $36.4 \%$ \\
\hline & Downward & 633 & $30.8 \%$ & 606 & $30.7 \%$ & 141 & $23.7 \%$ \\
\hline & Total & 2,053 & $100.0 \%$ & 1,977 & $100.0 \%$ & 596 & $100.0 \%$ \\
\hline \multirow{4}{*}{ Net Income } & Upward & 830 & $40.4 \%$ & 790 & $40.0 \%$ & 246 & $41.3 \%$ \\
\hline & Unchanged & 587 & $28.6 \%$ & 597 & $30.2 \%$ & 216 & $36.2 \%$ \\
\hline & Downward & 636 & $31.0 \%$ & 590 & $29.8 \%$ & 134 & $22.5 \%$ \\
\hline & Total & 2,053 & $100.0 \%$ & 1,977 & $100.0 \%$ & 596 & $100.0 \%$ \\
\hline
\end{tabular}

Note: This table summarizes the frequency of sales and earnings forecast revisions and of the forecast horizons. Of the 2,277 analyst reports reviewed, 2,053 reports provide one-year-ahead sales and earnings forecasts, 1,977 reports provide two-year-ahead sales and earnings forecasts, and 596 reports provide threeyear-ahead sales and earnings forecasts.

reported in a single analyst report, the report is treated as missing sales and earnings forecasts.

With regard to the 2,053 one-year-ahead sales forecasts, 995 (48.5\%) are upward revisions, 622 (30.3\%) are unchanged from previous forecasts, and 436 (21.2\%) are downward revisions. In sales forecasts, the number of upward revisions is more than twice the number of downward revisions. The forecast revisions of three types of earnings forecasts, operating profit, recurring profit, and net income, are more evenly distributed. For example, of the 2,053 one-year-ahead operating profit forecasts, 739 (36.0\%) are upward revisions, 662 (32.2\%) are unchanged from previous forecasts, and $652(31.8 \%)$ are downward revisions. The distribution of two- and three-year-ahead forecast revisions of earnings forecasts are similar to that of one-year-ahead forecast revisions. It appears that analysts simultaneously change the three types of earnings forecasts in the same direction.

One noticeable finding that is evident from Table 3 is that there are fewer reiterations in sales and earnings forecasts than stock ratings. Approximately $30 \%$ of sales and earnings forecasts are unchanged from previous forecasts, while over $80 \%$ of stock ratings are reiterations. This suggests that it takes more for analysts to change stock ratings than to revise sales and earnings forecasts. 


\section{Empirical Results}

\subsection{Information Content of Analysts' Stock Ratings}

First, I investigate the share price reaction to the release of analysts'stock rating information. The market reaction to an analyst report published on day 0 is measured as the compounded abnormal return over days 0 to $+1, C A R_{(0,+1)}$. This allows for a possible delay in the market's reaction to the release of new information contained in analyst reports. ${ }^{4}$ Daily abnormal returns are calculated using the conventional market model (Campbell, Lo, and McKinlay, 1996; MacKinlay, 1997). The market model parameters are generated from a 100-day estimation period from 130 trading days through 31 trading days before the release of the analyst report.

The market reactions to analysts' rating changes, analysts' rating levels, and both analysts' rating changes and levels are investigated using the following regressions.

$$
\begin{aligned}
C_{A A R_{(0,+1)}=} & \alpha_{1} U P G R A D E+\alpha_{2} R E I T E R A T E+\alpha_{3} D N G R A D E+\varepsilon, \\
C_{A R_{(0,+1)}=} & \alpha_{1} S T R B U Y+\alpha_{2} B U Y+\alpha_{3} H O L D E S E L L+\varepsilon, \text { and } \\
C A R_{(0,+1)}= & \alpha_{1} U P S T R B U Y+\alpha_{2} U P B U Y+\alpha_{3} R E S T R B U Y+\alpha_{4} R E B U Y+ \\
& \alpha_{5} R E H O L D S E L L+\alpha_{6} D N B U Y+\alpha_{7} D N H O L D S E L L+\varepsilon,
\end{aligned}
$$

where $U P G R A D E$ is an indicator variable taking the value of one if analysts' ratings are upgraded and zero otherwise, REITERATE is an indicator variable taking the value of one if analysts' rating are unchanged and zero otherwise, DNGRADE is an indicator variable taking the value of one if analysts' ratings are downgraded and zero otherwise, $S T R B U Y$ is an indicator variable taking the value of one if analysts' ratings are strong buy and zero otherwise, $B U Y$ is an indicator variable taking the value of one if analysts' ratings are buy and zero otherwise, HOLDSELL is an indicator variable taking the value of one if analysts' ratings are hold or sell and zero otherwise, UPSTRBUY is an indicator variable taking the value of one if analysts' ratings are upgraded to strong buy and zero otherwise, $U P B U Y$ is an indicator variable taking the value of one if analysts' ratings are upgraded to buy and zero otherwise, RESTRBUY is an indicator variable taking the value of one if analysts' ratings are unchanged from strong buy and zero otherwise, $R E B U Y$ is an indicator variable taking the value of one if analysts' ratings are unchanged from buy and zero otherwise, REHOLDSELL is an indicator variable taking the value of one if analysts' ratings are unchanged from hold or sell and zero otherwise, $D N B U Y$ is an indicator variable taking the value of one if analysts' ratings are downgraded to buy and zero otherwise, and DNHOLDSELL is an indicator variable taking the value of one if analysts' ratings are downgraded to hold or sell and zero otherwise.

The estimated results of Eqs. (1a), (1b), and (1c) are presented in Panel A of Table 4. The results of Eq. (1a) indicate that the ordering of market reactions to stock rating changes is consistent with expectations (UPGRADE > REITERATE > DOWNGRADE). The estimated coefficients show that upgrades, reiterations, and downgrades are associated with average market responses of $4.54 \%, 0.36 \%$, and $-4.18 \%$, respectively, and are all statistically significant at the $1 \%$ level. The results of estimating Eq. (1b) also exhibit the expected ordering of coefficients $(S T R B U Y>B U Y>H O L D S E L L)$. Strong

\footnotetext{
${ }^{4}$ The empirical results obtained in the following subsections are qualitatively similar when the abnormal return on day $0, A R_{(0)}$, and the compounded abnormal return over days -1 to $+1, C A R_{(-1,+1)}$, are used.
} 
Table 4: Information Content of Analysts' Stock Ratings

\begin{tabular}{|c|c|c|c|c|c|c|}
\hline \multicolumn{7}{|c|}{ Panel A: Information Content of Rating Levels and Changes } \\
\hline & \multicolumn{2}{|c|}{ (1a) } & \multicolumn{2}{|c|}{ (1b) } & \multicolumn{2}{|c|}{ (1c) } \\
\hline & Coefficient & $t$-statistic & Coefficient & $t$-statistic & Coefficient & $t$-statistic \\
\hline UPGRADE & 0.0454 & $11.40^{* *}$ & & & & \\
\hline REITERATE & 0.0036 & $3.71^{* *}$ & & & & \\
\hline$D N G R A D E$ & -0.0418 & $-8.179^{* *}$ & & & & \\
\hline STRBUY & & & 0.0192 & $5.11^{* *}$ & & \\
\hline$B U Y$ & & & 0.0075 & $4.98^{* *}$ & & \\
\hline HOLDSELL & & & -0.0040 & $-2.92^{* *}$ & & \\
\hline UPSTRBUY & & & & & 0.0635 & $5.51^{* *}$ \\
\hline$U P B U Y$ & & & & & 0.0435 & $8.99 * *$ \\
\hline RESTRBUY & & & & & 0.0154 & $4.04 * *$ \\
\hline REBUY & & & & & 0.0052 & $3.40^{* *}$ \\
\hline REHOLDESELL & & & & & 0.0002 & 0.16 \\
\hline$D N B U Y$ & & & & & -0.0206 & -1.83 \\
\hline DNHOLDSELL & & & & & -0.0457 & $-8.13^{* *}$ \\
\hline $\operatorname{adj} \cdot R^{2}$ & 0.1059 & & 0.0273 & & 0.1106 & \\
\hline$N$ & 2,053 & & 2,053 & & 2,053 & \\
\hline
\end{tabular}

Panel B: F tests for the Incremental Information Content of Rating Changes and Levels

Informativeness of rating changes conditional on rating levels: (1b) against (1c) $H_{0}: U P S T R B U Y=R E S T R B U Y, U P B U Y=R E B U Y=D N B U Y$, and $R E H O L D S E L L=D N H O L D S E L L$ $F$-statistic $\quad 48.97^{* *}$

Informativeness of rating levels conditional on rating changes: (1a) against (1c) $H_{0}: U P S T R B U Y=U P B U Y, R E S T R B U Y=R E B U Y=R E H O L D S E L L$, and $D N B U Y=D N H O L D S E L L$ F-statistic $\quad 3.66^{* *}$

Note: This table presents the results of estimating the following OLS regressions.

$C A R_{(0,+1)}=\alpha_{1} U P G R A D E+\alpha_{2} R E I T E R A T E+\alpha_{3} D N G R A D E+\varepsilon$,

$C A R_{(0,+1)}=\alpha_{1} S T R B U Y+\alpha_{2} B U Y+\alpha_{3} H O L D E S E L L+\varepsilon$, and

$C A R_{(0,+1)}=\alpha_{1} U P S T R B U Y+\alpha_{2} U P B U Y+\alpha_{3} R E S T R B U Y+\alpha_{4} R E B U Y+\alpha_{5} R E H O L D S E L L$

$+\alpha_{6} D N B U Y+\alpha_{7} D N H O L D S E L L+\varepsilon$

where $C A R_{(0,+1)}$ is the cumulative abnormal stock return (raw return minus the market model predicted return) over a two day window comprising the day of the analyst report release and the following trading day, UPGRADE is an indicator variable taking the value of one if analysts' ratings are upgraded and zero otherwise, REITERATE is an indicator variable taking the value of one if analysts' ratings are unchanged and zero otherwise, DNGRADE is an indicator variable taking the value of one if analysts' ratings are downgraded and zero otherwise, STRBUY is an indicator variable taking the value of one if analysts' ratings are strong buy and zero otherwise, $B U Y$ is an indicator variable taking the value of one if analysts' ratings are buy and zero otherwise, HOLDSELL is an indicator variable taking the value of one if analysts' ratings are hold or sell and zero otherwise, UPSTRBUY is an indicator variable taking the value of one if analysts' ratings are upgraded to strong buy and zero otherwise, $U P B U Y$ is an indicator variable taking the value of one if analysts' ratings are upgraded to buy and zero otherwise, RESTRBUY is an indicator variable taking the value of one if analysts' ratings are unchanged from strong buy and zero otherwise, $R E B U Y$ is an indicator variable taking the value of one if analysts' ratings are unchanged from buy and zero otherwise, REHOLDSELL is an indicator variable taking the value of one if analysts' ratings are unchanged from hold or sell and zero otherwise, DNBUY is an indicator variable taking the value of one if analysts' ratings are downgraded to buy and zero otherwise, and DNHOLDSELL is an indicator variable taking the value of one if analysts' ratings are downgraded to hold or sell and zero otherwise. $t$-statistics are calculated using White (1980) heteroskedasticity-consistent standard errors. ${ }^{* *}$ and ${ }^{*}$ represent two-tailed significance at the 0.01 and 0.05 levels. 
buy and buy ratings are associated with average price increases of $1.92 \%$ and $0.75 \%$, respectively, while hold/sell ratings are associated with an average price decline of $0.40 \%$. The estimated coefficients are also all statistically significant at the $1 \%$ level.

The results of Eqs. (1a) and (1b) indicate that analysts' stock rating changes and stock rating levels are both individually informative to the market. Eq. (1c) investigates the effects of rating changes and rating levels on market prices conditional on one another. The results of Eq. (1c) display an interesting ordering of estimated coefficients (UPSTRBUY > UPBUY > RESTRBUY > $R E B U Y>R E H O L D S E L L>D N B U Y>D N H O L D S E L L)$. This ordering suggests that the direction of rating changes (upgrade, reiteration, and downgrade) is a more decisive factor in explaining the market reaction than the level of analysts' ratings (strong buy, buy, and hold/sell). However, when the direction of rating changes is the same, the rating level appears to determine the magnitude of the market reaction. For example, when newly released analysts' ratings are unchanged from the previous ratings (RESTRBUY, REBUY, and REHOLDSELL), reiterations of strong buy, buy, and hold/sell ratings are associated with average market responses of $1.54 \%, 0.52 \%$, and $0.02 \%$, respectively. This is true with rating upgrades as well as rating downgrades. Upgrades to strong buy trigger a higher average price rise than upgrades to buy, $6.35 \%$ versus $4.35 \%$, while downgrades to hold/sell evoke a further average price decline than downgrades to buy, $-4.57 \%$ versus $-2.06 \%$.

The $F$-tests reported in Panel B of Table 4 investigate whether the changes in and levels of analysts' ratings explain stock returns conditional on one another by comparing the explanatory power of Eq. (1c) with that of Eqs. (1b) and (1a). First, if the rating change is an important factor in explaining share price reactions beyond the rating level, then the null hypothesis of UPSTRBUY $=$ RESTRBUY, UPBUY = REBUY = DNBUY, and REHOLDSELL = DNHOLDSELL would be rejected. The $F$-test comparing the explanatory power of Eq. (1b) with that of Eq. (1c) rejects the null hypothesis at the $1 \%$ level $(F$-statistic $=48.97)$, which indicates the incremental informativeness of rating changes conditional on rating levels. Next, if the rating level adds explanatory power beyond that conveyed by the rating change, then the null hypothesis of UPSTRBUY =UPBUY, RESTRBUY $=R E B U Y=R E H O L D S E L L$, and DNBUY = DNHOLDSELL would be rejected. The F-test comparing the explanatory power of Eq. (1a) with that of Eq. (1c) rejects the null hypothesis at the $1 \%$ level $(F$-statistic $=3.66)$, thereby suggesting the incremental informativeness of rating levels conditional on rating changes. Overall, the results of the joint tests in Panel B indicate that both rating changes and rating levels have incremental information content over one another.

\subsection{Information Content of Analysts' Sales and Earnings Forecasts}

Next, I investigate the share price reaction to the release of analysts' sales and earnings forecast information. The sales and earnings forecast revisions are defined as

$$
\text { Forecast Revison }=\frac{\text { Current analyst forecast }- \text { Previous analyst forecast }}{M V E \text { at the beginning of the fiscal year }} \text {, }
$$

where both current and previous analysts' forecasts are one-year-ahead sales and earnings forecasts reported in a single analyst report.

Using the forecast revisions defined above, the following regressions are estimated.

$$
C A R_{(0,+1)}=\beta_{0}+\beta_{1} \Delta S A L E S+\varepsilon
$$




$$
\begin{aligned}
\operatorname{CAR}_{(0,+1)}= & \beta_{0}+\beta_{1} \Delta O P E P R O F I T+\varepsilon \\
\operatorname{CAR}_{(0,+1)}= & \beta_{0}+\beta_{1} \Delta R E C U R P R O F I T+\varepsilon \\
C A R_{(0,+1)}= & \beta_{0}+\beta_{1} \Delta N E T I N C O M E+\varepsilon, \text { and } \\
C_{A R R_{(0,+1)}=} & \beta_{0}+\beta_{1} \Delta S A L E S+\beta_{2} \Delta O P E P R O F I T+\beta_{3} \Delta R E C U R P R O F I T+ \\
& \beta_{4} \Delta N E T I N C O M E+\varepsilon
\end{aligned}
$$

where $\triangle S A L E S$ is a revision of analysts' one-year-ahead sales forecasts deflated by the MVE at the beginning of the fiscal year, $\triangle O P E P R O F I T$ is a revision of analysts' one-year-ahead operating profit forecasts deflated by the MVE at the beginning of the fiscal year, $\triangle R E C U R P R O F I T$ is a revision of analysts' one-year-ahead recurring profit forecasts deflated by the MVE at the beginning of the fiscal year, and $\triangle N E T I N C O M E$ is a revision of analysts' one-year-ahead net income forecasts deflated by the MVE at the beginning of the fiscal year.

The results of estimating Eqs. (2a) through (2e) are presented in Table 5. The estimated coefficients of Eqs. (2a) through (2d) are all statistically significantly positive at the 5\% level or higher, which suggests that sales and the three types of earnings forecasts are all informative to the stock market on a stand-alone basis. However, in terms of the explanatory power of these regressions, $\triangle R E C U R P R O F I T$ has the highest adj. $R^{2}$ value, 0.0807 , followed by 0.0760 for $\triangle O P E P R O F I T$, 0.0282 for $\triangle N E T I N C O M E$, and 0.0058 for $\triangle S A L E S$. It appears that analysts' recurring profit forecasts are more informative to the market than sales and other earnings forecasts. When all four variables ( $\triangle S A L E S, \triangle O P E P R O F I T, \triangle R E C U R P R O F I T$, and $\triangle N E T I N C O M E$ ) are included in the regression model (2e), only the estimated coefficient of $\triangle R E C U R P R O F I T$ remains statistically significant, $0.7330(t$-statistic $=2.99)$, while those of other variables become insignificant.

The results of both univariate and multivariate tests indicate that among analysts' sales and the three types of earnings forecasts, recurring profit forecasts provide the most valuable information to the market. On the basis of this finding, I use analysts' recurring profit forecasts as analysts' earnings forecasts in the following analysis.

\subsection{Information Content of Analysts' Stock Ratings and Earnings Forecasts}

Thus far, the analysis has investigated the information content of analysts' stock ratings and earnings forecast revisions separately. In this section, I examine the market reaction to analysts' rating changes, rating levels, and earnings forecast revisions, each of which is conditional on the others. I augment Eq. (1c) by adding revisions of analysts' one-year-ahead recurring profit forecasts $(\triangle R E C U R P R O F I T)$, which I use here as a proxy for analysts' earnings forecast revisions $(\triangle A E F)$.

$$
\begin{aligned}
C A R_{(0,+1)}= & \gamma_{1} U P S T R B U Y+\gamma_{2} U P B U Y+\gamma_{3} R E S T R B U Y+\gamma_{4} R E B U Y+\gamma_{5} R E H O L D S E L L+ \\
& \gamma_{6} D N B U Y+\gamma_{7} D N H O L D S E L L+\gamma_{8} \triangle A E F+\varepsilon,
\end{aligned}
$$

where UPSTRBUY is an indicator variable taking the value of one if analysts' ratings are upgraded to strong buy and zero otherwise, UPBUY is an indicator variable taking the value of one if analysts' ratings are upgraded to buy and zero otherwise, RESTRBUY is an indicator variable taking the value of one if analysts' ratings are unchanged from strong buy and zero otherwise, $R E B U Y$ is an indicator variable taking the value of one if analysts' ratings are unchanged from buy and zero otherwise, 
Table 5: Information Content of Analysts' Sales and Earnings Forecasts

\begin{tabular}{|c|c|c|c|c|c|}
\hline & (2a) & (2b) & $(2 c)$ & $(2 \mathrm{~d})$ & $(2 \mathrm{e})$ \\
\hline Intercept & $\begin{array}{c}0.0019 \\
(1.72)\end{array}$ & $\begin{array}{l}0.0038 \\
(4.01)^{* *}\end{array}$ & $\begin{array}{l}0.0037 \\
(3.86)^{* *}\end{array}$ & $\begin{array}{l}0.0031 \\
(3.13)^{* *}\end{array}$ & $\begin{array}{l}0.0037 \\
(3.54)^{* *}\end{array}$ \\
\hline$\triangle S A L E S$ & $\begin{array}{l}0.0614 \\
(2.22)^{*}\end{array}$ & & & & $\begin{array}{r}0.0050 \\
(0.22)\end{array}$ \\
\hline$\triangle O P E P R O F I T$ & & $\begin{array}{l}0.9104 \\
(3.98)^{* *}\end{array}$ & & & $\begin{array}{r}0.2336 \\
(0.79)\end{array}$ \\
\hline$\triangle R E C U R P R O F I T$ & & & $\begin{array}{l}0.9042 \\
(4.27)^{* *}\end{array}$ & & $\begin{array}{l}0.7330 \\
(2.99)^{* *}\end{array}$ \\
\hline$\triangle N E T I N C O M E$ & & & & $\begin{array}{l}0.5090 \\
(2.64)^{* * *}\end{array}$ & $\begin{array}{r}-0.0671 \\
(-0.63)\end{array}$ \\
\hline $\operatorname{adj} . R^{2}$ & 0.0058 & 0.0760 & 0.0807 & 0.0282 & 0.0804 \\
\hline$N$ & 2,053 & 2,053 & 2,053 & 2,053 & 2,053 \\
\hline
\end{tabular}

Note: This table presents the results of estimating the following OLS regressions.

$C A R_{(0,+1)}=\beta_{0}+\beta_{1} \triangle S A L E S+\varepsilon$,

$C A R_{(0,+1)}=\beta_{0}+\beta_{1} \triangle O P E P R O F I T+\varepsilon$,

$C A R_{(0,+1)}^{(0,+)}=\beta_{0}+\beta_{1} \triangle R E C U R P R O F I T+\varepsilon$,

$C A R_{(0,+1)}=\beta_{0}+\beta_{1} \triangle N E T I N C O M E+\varepsilon$, and

$C A R_{(0,+1)}=\beta_{0}+\beta_{1} \Delta S A L E S+\beta_{2} \Delta O P E P R O F I T+\beta_{3} \Delta R E C U R P R O F I T+\beta_{4} \Delta N E T I N C O M E+\varepsilon$,

where $C A R_{(0,+1)}$ is the cumulative abnormal stock return (raw return minus the market model predicted return) over a two day window comprising the day of the analyst report release and the following trading day, $\triangle S A L E S$ is a revision of analysts' one-year-ahead sales forecasts deflated by the MVE at the beginning of the fiscal year, $\triangle O P E P R O F I T$ is a revision of analysts' one-year-ahead operating profit forecasts deflated by the MVE at the beginning of the fiscal year, $\triangle R E C U R P R O F I T$ is a revision of analysts' one-year-ahead recurring profit forecasts deflated by the MVE at the beginning of the fiscal year, and $\triangle N E T I N C O M E$ is a revision of analysts' one-year-ahead net income forecasts deflated by the MVE at the beginning of the fiscal year. $t$-statistics are provided in parentheses below the coefficient estimates and are calculated using White (1980) heteroskedasticity-consistent standard errors. ${ }^{* *}$ and ${ }^{*}$ represent two-tailed significance at the 0.01 and 0.05 levels.

REHOLDSELL is an indicator variable taking the value of one if analysts' ratings are unchanged from hold or sell and zero otherwise, $D N B U Y$ is an indicator variable taking the value of one if analysts' ratings are downgraded to buy and zero otherwise, DNHOLDSELL is an indicator variable taking the value of one if analysts' ratings are downgraded to hold or sell and zero otherwise, and $\triangle A E F$ is a revision of analysts' one-year-ahead recurring profit forecasts deflated by the MVE at the beginning of the fiscal year.

The estimated results of Eq. (3) are presented in the third column of Panel A of Table 6. The first and second columns of Panel A show the estimated results of Eqs. (1c) and (2c) for reference purposes. The results of Eq. (3) do not materially differ from the combined results of Eqs. (1c) and (2c). The ordering of the estimated coefficients for analysts' rating variables remains the same, UPSTRBUY > UPBUY > RESTRBUY > REBUY > REHOLDSELL > DNBUY > DNHOLDSELL, which indicates the primary and secondary roles that rating changes and rating levels play in explaining stock price reactions. The estimated coefficient of $\triangle A E F$ is also statistically significantly positive, $0.6762(t$-statistic $=3.66)$, thereby suggesting the informativeness of analysts' earnings forecast revisions after controlling for the information in analysts' ratings. 
Table 6: Information Content of Analysts' Stock Ratings and Earnings Forecasts

\begin{tabular}{|c|c|c|c|c|c|c|}
\hline \multicolumn{7}{|c|}{ Panel A: Information Content of Rating Changes, Rating Levels, and Analysts' Earnings Forecasts } \\
\hline & \multicolumn{2}{|c|}{ (1c) } & \multicolumn{2}{|c|}{$(2 c)$} & \multicolumn{2}{|c|}{$(3)$} \\
\hline & Coefficient & $t$-statistic & Coefficient & $t$-statistic & Coefficient & $t$-statistic \\
\hline UPSTRBUY & 0.0635 & $5.51^{* *}$ & & & 0.0601 & $5.13^{* *}$ \\
\hline$U P B U Y$ & 0.0435 & $8.99^{* *}$ & & & 0.0408 & $8.49^{* *}$ \\
\hline RESTRBUY & 0.0154 & $4.04^{* *}$ & & & 0.0146 & $3.88^{* *}$ \\
\hline$R E B U Y$ & 0.0052 & $3.40^{* *}$ & & & 0.0048 & $3.22 *$ \\
\hline REHOLDESELL & 0.0002 & 0.16 & & & 0.0013 & 1.00 \\
\hline$D N B U Y$ & -0.0206 & -1.83 & & & -0.0153 & -1.33 \\
\hline DNHOLDSELL & -0.0457 & $-8.13^{* *}$ & & & -0.0344 & $-6.55^{* *}$ \\
\hline$\triangle A E F$ & & & 0.9042 & $4.27^{* * *}$ & 0.6762 & $3.66^{* *}$ \\
\hline $\operatorname{adj} \cdot R^{2}$ & 0.1106 & & 0.0807 & & 0.1519 & \\
\hline$N$ & 2,053 & & 2,053 & & 2,053 & \\
\hline
\end{tabular}

Panel B: F tests for the Incremental Information Content of Rating Changes and Levels

Informativeness of rating changes conditional on rating levels and $\triangle A E F$

$H_{0}: U P S T R B U Y=R E S T R B U Y, U P B U Y=R E B U Y=D N B U Y$, and $R E H O L D S E L L=D N H O L D S E L L$

$F$-statistic $\quad 33.82^{* *}$

Informativeness of rating levels conditional on rating changes and $\triangle A E F$

$H_{0}: U P S T R B U Y=U P B U Y, R E S T R B U Y=R E B U Y=R E H O L D S E L L$, and $D N B U Y=D N H O L D S E L L$

$F$-statistic

$2.44^{*}$

Note: This table presents the results of estimating the following OLS regressions.

$C A R_{(0,+1)}=\alpha_{1} U P S T R B U Y+\alpha_{2} U P B U Y+\alpha_{3} R E S T R B U Y+\alpha_{4} R E B U Y+\alpha_{5} R E H O L D S E L L+$ $\alpha_{6} D N B U Y+\alpha_{7} D N H O L D S E L L+\varepsilon$,

$C A R_{(0,+1)}=\beta_{0}+\beta_{1} \triangle A E F+\varepsilon$, and

$C A R_{(0,+1)}=\gamma_{1} U P S T R B U Y+\gamma_{2} U P B U Y+\gamma_{3} R E S T R B U Y+\gamma_{4} R E B U Y+\gamma_{5} R E H O L D S E L L+\gamma_{6} D N B U Y+$

$\gamma_{7} D N H O L D S E L L+\gamma_{8} \triangle A E F+\varepsilon$,
where $C A R_{(0,+1)}$ is the cumulative abnormal stock return (raw return minus the market model predicted return) over a two day window comprising the day of the analyst report release and the following trading day, UPSTRBUY is an indicator variable taking the value of one if analysts' ratings are upgraded to strong buy and zero otherwise, $U P B U Y$ is an indicator variable taking the value of one if analysts' ratings are upgraded to buy and zero otherwise, RESTRBUY is an indicator variable taking the value of one if analysts' ratings are unchanged from strong buy and zero otherwise, $R E B U Y$ is an indicator variable taking the value of one if analysts' ratings are unchanged from buy and zero otherwise, REHOLDSELL is an indicator variable taking the value of one if analysts' ratings are unchanged from hold or sell and zero otherwise, $D N B U Y$ is an indicator variable taking the value of one if analysts' ratings are downgraded to buy and zero otherwise, DNHOLDSELL is an indicator variable taking the value of one if analysts' ratings are downgraded to hold or sell and zero otherwise, and $\triangle A E F$ is a revision of analysts' one-year-ahead recurring profit forecasts deflated by the MVE at the beginning of the fiscal year. $t$-statistics are calculated using White (1980) heteroskedasticity-consistent standard errors. ${ }^{* *}$ and * represent two-tailed significance at the 0.01 and 0.05 levels.

In order to further examine the incremental information content of rating changes and rating levels, two $F$-tests are conducted and the results are reported in Panel B of Table 6. The first $F$-test investigates the incremental informativeness of rating changes conditional on rating levels and analysts' earnings forecast revisions, and the second $F$-test examines the incremental informativeness of rating levels conditional on rating changes and analysts' earnings forecast revisions. The two 
$F$-statistics in Panel B, 33.82 and 2.44, both reject the null hypotheses of no incremental information content of rating changes and rating levels at the $5 \%$ level or higher. Overall, these results indicate that neither analysts' stock ratings nor analysts' earnings forecast revisions subsume the information of the other.

\subsection{Timing and Frequency of Analyst Report Publications}

Most analyst reports published in Japan include information on management sales and earnings forecasts along with analysts' forecasts. In fact, of the 2,053 analyst reports examined, 2,037 (99.2\%) contained the figures of the most recently publicized management forecasts. This is because Japanese firms are required by the stock exchange disclosure guidelines to provide one-year-ahead sales and earnings forecasts at quarterly and annual earnings announcements. In addition, when a significant change in previously published forecasts arises ( $\pm 10 \%$ of sales forecasts, $\pm 30 \%$ of earnings forecasts), corporate managers in Japan are required to announce revised forecasts immediately. A survey conducted in 2006 reveales that 3,790 of the 3,831 listed firms (98.9\%) provided management forecasts in that year. Thus, management forecasts are publicly available in Japan and existing evidence documents that they provide valuable information to financial analysts and investors (Conroy, Harris, and Park, 1998; Conroy, Eades, and Harris, 2000; Ota, 2010).

This section examines the timing and frequency of analyst report publications relative to the announcement dates of management earnings forecasts. I compute the number of trading days between the analyst report publication date and the previously and subsequently announced management forecast date. Figure $1(\mathrm{~A})$ presents the frequency of analyst reports at various points in time relative to the following announcement of management forecasts. It is clear from the figure that few reports are published before the releases of management forecasts. In fact, only 43 of the 2,037 analyst reports are published within 10 trading days (two weeks) before the release of management forecasts. The figure also reveals that the issuance of analyst reports is concentrated in the interval between 50 and 69 trading days before the release of the following management forecasts. The average (median) number of trading days between the analyst report publication date and the subsequent management forecast announcement date is 55.9 (58.0).

Figure 1(B) presents the frequency of analyst reports at various points in time relative to the most recently announced management forecasts. It is evident from the figure that over half of the analyst reports (1,062 of 2,037 or $52.1 \%$ of all reports) are published on the day after the management forecast announcement. A high frequency of analyst report publications is also observed over the next several days. The average (median) number of trading days between the analyst report publication date and the most recent management forecast announcement date is 10.7 (1.0). The finding that over half of the analyst report publications are driven by the public announcement of management forecasts is not exactly unexpected, as a majority of management forecasts are released at quarterly and annual earnings announcements and earlier studies document that analysts' ratings and earnings forecast revisions are concentrated on the earnings announcement day and following several days (Stickel, 1989; Bowen, Davis, and Matsumoto, 2002; Ivković and Jegadeesh, 2004). This is also consistent with the finding shown in Figure 1(A) that a large fraction of analyst reports are published 50 to 69 trading days (10 to 14 weeks) before the following announcement of management forecasts because the length of the period corresponds approximately to the length of a fiscal quarter.

One aspect of the release of management forecasts and analyst reports that requires special attention is the time of day when they are published. Stock exchanges in Japan require listed companies to make timely disclosures of material corporate information such as financial results and 
Figure 1(A): Frequency of Analyst Reports Prior to The Issuance of Management Forecasts

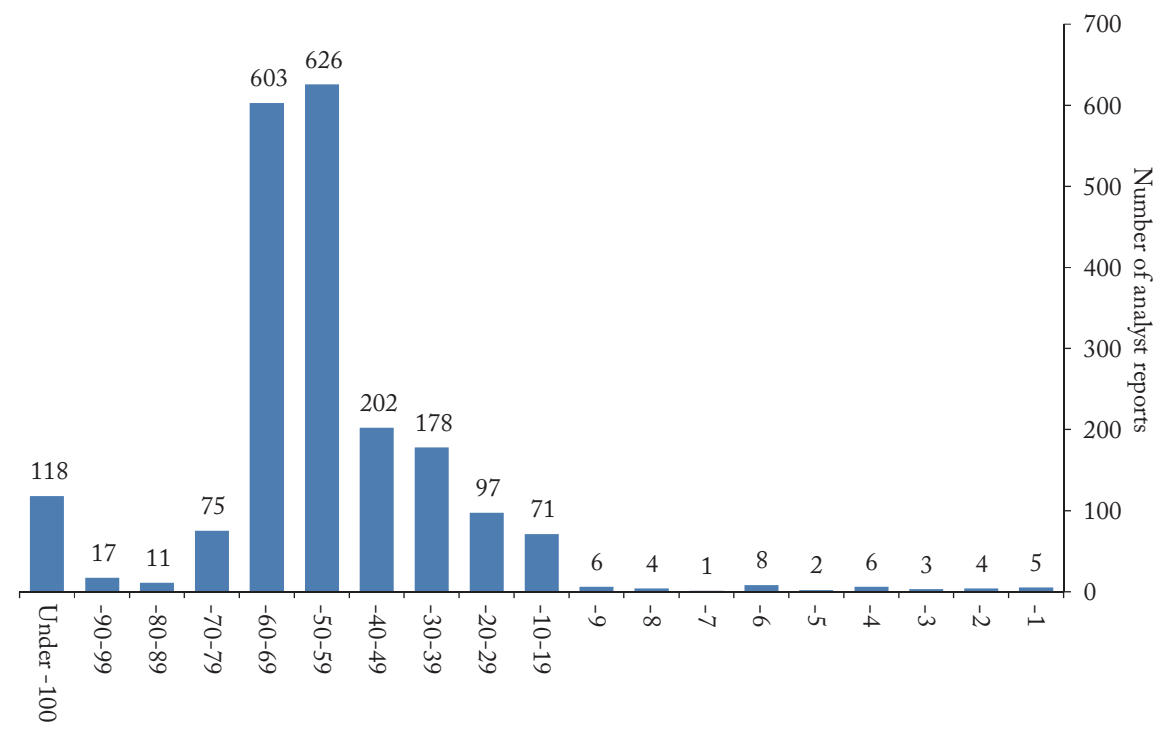

Trading days until the following management forecast announcement

Note: This figure presents the frequency of analyst reports at various points in time relative to the following management forecast announcement date. The total number of analyst reports with management forecast information is 2,037.

Figure 1(B): Frequency of Analyst Reports Subsequent to The Issuance of Management FORECASTS

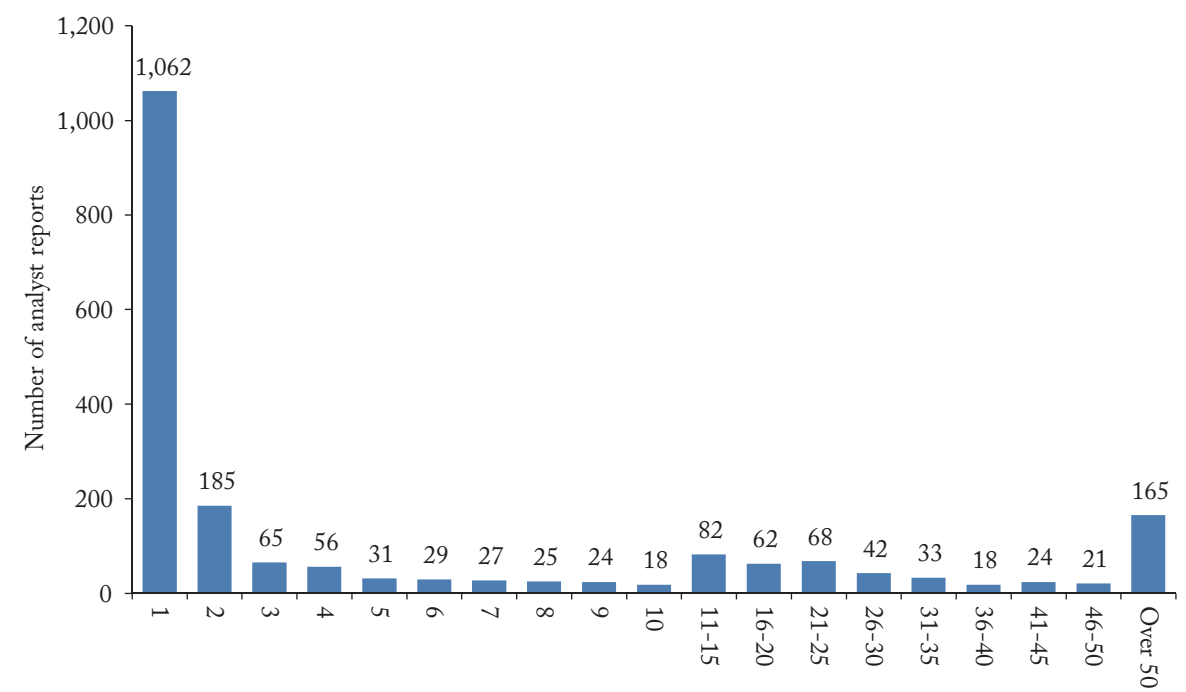

Trading days after the previous management forecast announcement

Note: This figure presents the frequency of analyst reports at various points in time relative to the most recent management forecast announcement date. The total number of analyst reports with management forecast information is 2,037 . 
forecasts through the Timely Disclosure Network (TDnet). Once the information is disclosed on TDnet for public inspection, trading in shares based on the information is exempt from the insider trading regulation. The Company Announcement Disclosure Service, which is a part of TDnet, keeps records of such disclosed information, and the database shows that the vast majority of company announcements are made public after the market closes at 3 p.m. and particularly on Fridays. This is presumably done to give the market sufficient time to digest newly released information and to avoid sudden fluctuations in stock prices. As a result, there is a one-day discrepancy between the management forecast announcement date and the date when the market actually incorporates the information. On the other hand, analyst reports are usually prepared and disseminated to clients in the early morning before the market opens at 9 a.m. Thus, the 1,062 analyst reports that are published the day after the announcement of management forecasts are released practically simultaneously with management forecasts.

\subsection{Information Content of Analysts' Forecasts in the Presence of Concurrently Announced Management Forecasts}

In the following sections, I use the subsample of analyst reports published the day after the announcement of management forecasts, which are the 1,062 analyst reports in Figure 1(B). The simultaneously announced subsample provides an ideal opportunity, with less concern for other events taking place, to investigate the incremental information content of analysts' ratings and earnings forecasts conditional on the publicly available management forecast information. There are three cases where concurrent announcements occur, and different treatments must be applied in each case.

\section{Case 1: Simultaneous releases of analyst reports and management forecasts at quarterly earnings announcements.}

This is probably the most contaminated case of the three. Since only annual earnings forecasts are provided by both analysts and management, the surprise element in actual quarterly earnings cannot be controlled for. However, it can be argued that if there is a surprise in actual quarterly earnings, it may be reflected in the company's contemporaneously released annual earnings forecasts. Figure 2(A) illustrates the decomposition of surprise elements at quarterly earnings announcements. I divide the revision of analysts' earnings forecasts, $\triangle A E F$, into two components, $\triangle M E F \_P A E F$ and $\triangle A E F \_M E F$. The former is the difference between current management earnings forecasts $(M E F)$ and previous analysts' earnings forecasts $(P A E F)$, and the latter is the difference between current analysts' earnings forecasts $(A E F)$ and current management forecasts $(M E F)$. As with $\triangle A E F$, both variables are deflated by the MVE at the beginning of the fiscal year. The former component represents the surprise element brought by the release of new management earnings forecasts, while the latter captures the surprise element conveyed by the publication of new analysts' earnings forecasts. If analysts' earnings forecasts have informational value beyond concurrently released management earnings forecasts, $\triangle A E F \_M E F$ will add some explanatory power in explaining share price reactions. I use the following regression model to investigate the impact.

$$
\begin{aligned}
C A R_{(0,+1)}= & \delta_{1} U P S T R B U Y+\delta_{2} U P B U Y+\delta_{3} R E S T R B U Y+\delta_{4} R E B U Y+\delta_{5} R E H O L D S E L L+ \\
& \delta_{6} D N B U Y+\delta_{7} D N H O L D S E L L+\delta_{8} \triangle M E F_{-} P A E F+\delta_{9} \triangle A E F \_M E F+\varepsilon,
\end{aligned}
$$




\section{Figure 2(A): Decomposition of Surprise Elements in Cases 1 and 3}

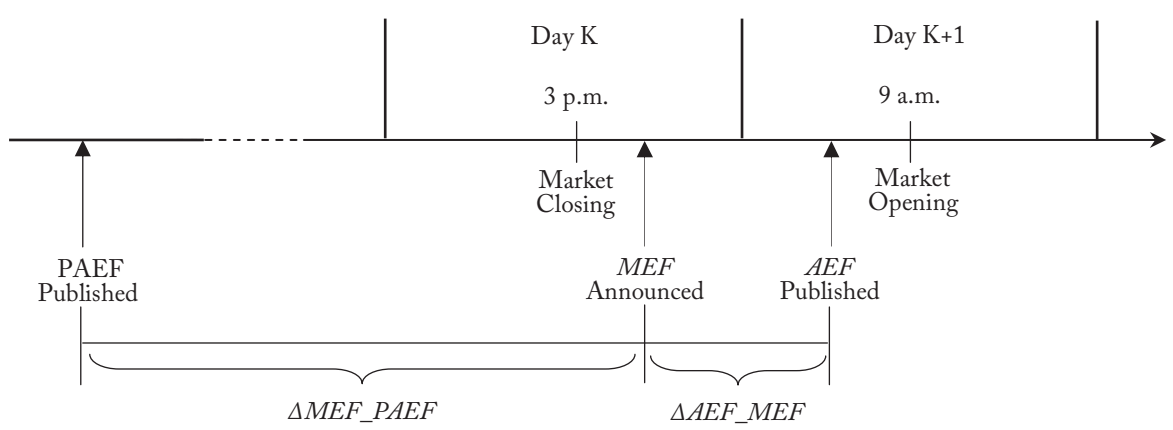

Note: This figure illustrates the decomposition of surprise elements at quarterly earnings announcements (Case 1$)$ and at announcements of revisions of management forecasts (Case 3). $\triangle M E F \_P A E F=M E F-P A E F$ and $\triangle A E F \_M E F=$ $A E F-M E F$, where $M E F$ is management recurring profit forecasts, $A E F$ is analysts' recurring profit forecasts, and $P A E F$ is analysts' previous recurring profit forecasts. All forecasts are one-year-ahead annual forecasts and are deflated by the MVE at the beginning of the fiscal year.

\section{Figure 2(B): Decomposition of Surprise Elements in Case 2}

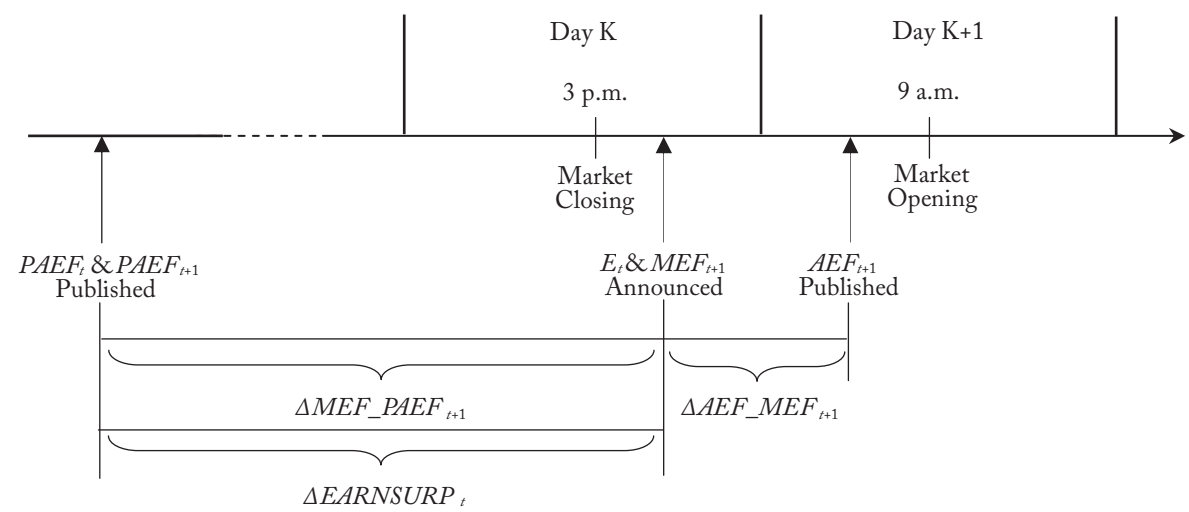

Note: This figure illustrates the decomposition of surprise elements at annual earnings announcements (Case 2). $\triangle M E F_{-}$ $P A E F_{t+1}=M E F_{t+1}-P A E F_{t+1}, \triangle A E F_{-} M E F_{t+1}=A E F_{t+1}-M E F_{t+1}$, and $\triangle E A R N S U R P_{t}=E_{t}-P A E F_{t}$, where $M E F_{t+1}$ is management recurring profit forecasts for year $t+1, P A E F_{t+1}$ is analysts' previous recurring profit forecasts for year $t+1$, $A E F_{t+1}$ is analysts' recurring profit forecasts for year $t+1, E_{t}$ is actual recurring profit for year $t$, and $P A E F_{t}$ is analysts' previous recurring profit forecasts for year $t$. All forecasts are one-year-ahead annual forecasts except for $P A E F_{t+1}$, which are two-year-ahead annual forecasts at the time of the publication. All variables are deflated by the MVE at the beginning of the fiscal year.

where UPSTRBUY is an indicator variable taking the value of one if analysts' ratings are upgraded to strong buy and zero otherwise, UPBUY is an indicator variable taking the value of one if analysts' ratings are upgraded to buy and zero otherwise, RESTRBUY is an indicator variable taking the value 
of one if analysts' ratings are unchanged from strong buy and zero otherwise, $R E B U Y$ is an indicator variable taking the value of one if analysts' ratings are unchanged from buy and zero otherwise, REHOLDSELL is an indicator variable taking the value of one if analysts' ratings are unchanged from hold or sell and zero otherwise, $D N B U Y$ is an indicator variable taking the value of one if analysts' ratings are downgraded to buy and zero otherwise, DNHOLDSELL is an indicator variable taking the value of one if analysts' ratings are downgraded to hold or sell and zero otherwise, $\triangle M E F_{-}$ $P A E F$ is management recurring profit forecasts minus analysts' previous recurring profit forecasts $(M E F-P A E F)$ deflated by the MVE at the beginning of the fiscal year, and $\triangle A E F \_M E F$ is analysts' recurring profit forecasts minus management recurring profit forecasts $(A E F-M E F)$ deflated by the $\mathrm{MVE}$ at the beginning of the fiscal year. All earnings forecasts are one-year-ahead annual forecasts.

\section{Case 2: Simultaneous releases of analyst reports and management forecasts at annual earnings announcements.}

This is the most complicated case of the three. In addition to the two types of earnings forecasts for the upcoming year, $M E F$ and $A E F$, actual earnings for the recently completed year are also announced at the same time. Figure 2(B) depicts the surprise elements at annual earnings announcements. As with Case 1, I use $\triangle M E F \_P A E F$ and $\triangle A E F \_M E F$ to capture the surprise components brought by two current earnings forecasts. For the surprise element conveyed by actual earnings, I define $\triangle E A R N S U R P$ as the difference between actual earnings and previous analysts' earnings forecasts for the recently completed year. The following regression is used to assess these impacts.

$$
\begin{aligned}
C A R_{(0,+1)}= & \delta_{1} U P S T R B U Y+\delta_{2} U P B U Y+\delta_{3} R E S T R B U Y+\delta_{4} R E B U Y+\delta_{5} R E H O L D S E L L+ \\
& \delta_{6} D N B U Y+\delta_{7} D N H O L D S E L L+\delta_{8} \Delta M E F \_P A E F+\delta_{9} \triangle A E F \_M E F+ \\
& \delta_{10} \Delta E A R N S U R P+\varepsilon,
\end{aligned}
$$

where $\triangle E A R N S R U P$ is actual recurring profit for the recently completed year minus previous analysts' recurring profit forecasts for the recently completed year deflated by the MVE at the beginning of the recently completed year. The definitions of other variables are the same as those in Eq. (4).

Case 3: Simultaneous releases of analyst reports and management forecasts at announcements of revisions of management earnings forecasts.

This is the ideal case of the three for inspecting the respective informativeness of analysts' and management earnings forecasts. Companies' managers are required by the disclosure guidelines prescribed by the stock exchanges to announce revised forecasts immediately when there is a significant change in previously published forecasts $( \pm 10 \%$ of sales forecasts and $\pm 30 \%$ of earnings forecasts). Thus, the forecast revisions occur without prior notice and usually without other concurrent announcements. The regression model employed in Case 3 is the same as Case 1, which is Eq. (4). Only the sample observations used for estimation differ between Case 3 and Case 1.

The results of the analysis using the subsample of 1,062 analyst reports issued simultaneously with management forecasts are presented in Table 7. The first and second columns in Panel A show the results of estimating Eqs. (3) and (4) using all observations in the subsample. Eq. (3) ignores 
the management earnings forecast information contained in analyst reports and uses revisions of analysts' earnings forecasts, $\triangle A E F$, while Eq. (4) includes the management forecast information and splits $\triangle A E F$ into two components, $\triangle M E F \_P A E F$ and $\triangle A E F \_M E F$. The estimation results of Eq. (3) are similar to those reported in Table 6. The estimated coefficient of $\triangle A E F$ is significantly positive, 1.3159 , indicating the informativeness of analysts' earnings forecasts. The results of Eq. (4) show that the estimated coefficients of $\triangle M E F \_P A E F$ and $\triangle A E F \_M E F$ are 1.3464 and 1.1256 , respectively, and are both significant at the $1 \%$ level. These findings indicate that neither companies' earnings forecasts nor analysts' earnings forecasts subsume the information of the other.

Panel B of Table 7 reports the results of two $F$-tests that investigate the incremental information content of rating changes and rating levels using Eq. (4) with all observations in the subsample. The first $F$-test examines the incremental information content of rating changes conditional on rating levels and management and analysts' earnings forecasts. The $F$-statistic obtained is 13.17 , which is significant at the $1 \%$ level. This indicates the incremental informativeness of rating changes beyond information contained in rating levels and two types of earnings forecasts. The second $F$-test investigates the incremental information content of rating levels conditional on rating changes and two types of earnings forecasts. It rejects the null hypothesis of no information content of rating levels at the $10 \%$ level ( $F$-statistic $=2.28$ ). These somewhat weaker results of the two $F$-tests, compared with those reported in Table 6, may be attributed to the reduction in the sample size. The ordering of the estimated coefficients for analysts' stock rating variables remains the same, UPSTRBUY > UPBUY > RESTRBUY > REBUY > REHOLDSELL $>D N B U Y>D N H O L D S E L L$, thereby suggesting the primary and secondary roles of rating changes and rating levels in explaining stock price reactions.

The third, fourth, and fifth columns of Panel A of Table 7 present the estimated results for Cases 1, 2, and 3, respectively. Of the 1,062 analyst reports that are issued contemporaneously with management forecasts, 694 are announced at quarterly earnings announcements (Case 1), 217 at annual earnings announcements (Case 2), and 151 at announcements of revisions of management forecasts (Case 3). The estimation results of Eq. (4) in Case 1 are similar to those with all observations in the second column. The estimated coefficients of $\triangle M E F \_P A E F$ and $\triangle A E F \_M E F$ are both significantly positive, 0.9671 and 1.0593 , which indicates the incremental informativeness of analysts' earnings forecasts conditional on management earnings forecasts, and vice versa. One notable finding in Case 1 is that adj. $R^{2}$ is 0.0977 , which is much lower than the other two cases. The low explanatory power in Case 1 may be attributed to the lack of control for the impact of the announcement of actual quarterly earnings.

The estimation results of Eq. (5) in Case 2 reveal that while the estimated coefficients of $\triangle M E F \_P A E F$ and $\triangle A E F \_M E F$ are both significantly positive, 1.4973 and 0.9039 , the coefficient of $\triangle E A R N S U R P$ is positive, 0.1040 , but not statically significant. These findings suggest that the announcement of actual annual earnings does not convey valuable information to the market beyond information contained in corporate managers' next-year earnings forecasts and analysts' forecasts. This is not unpredicted considering the results reported in prior research. For example, Conroy et al. (1998) and Conroy et al. (2000) document that the market reaction to the surprise component of management earnings forecasts is much more pronounced than to the unexpected component of actual earnings at annual earnings announcements. Ota (2010) also finds that the value relevance of actual earnings almost disappears once the impact of management earnings forecasts is accounted for. It appears that the market is more concerned with analysts' and corporate insiders' views of future earnings than the mere publication of historical numbers.

There are only 151 observations for estimating Eq. (4) in Case 3, and they contain neither 


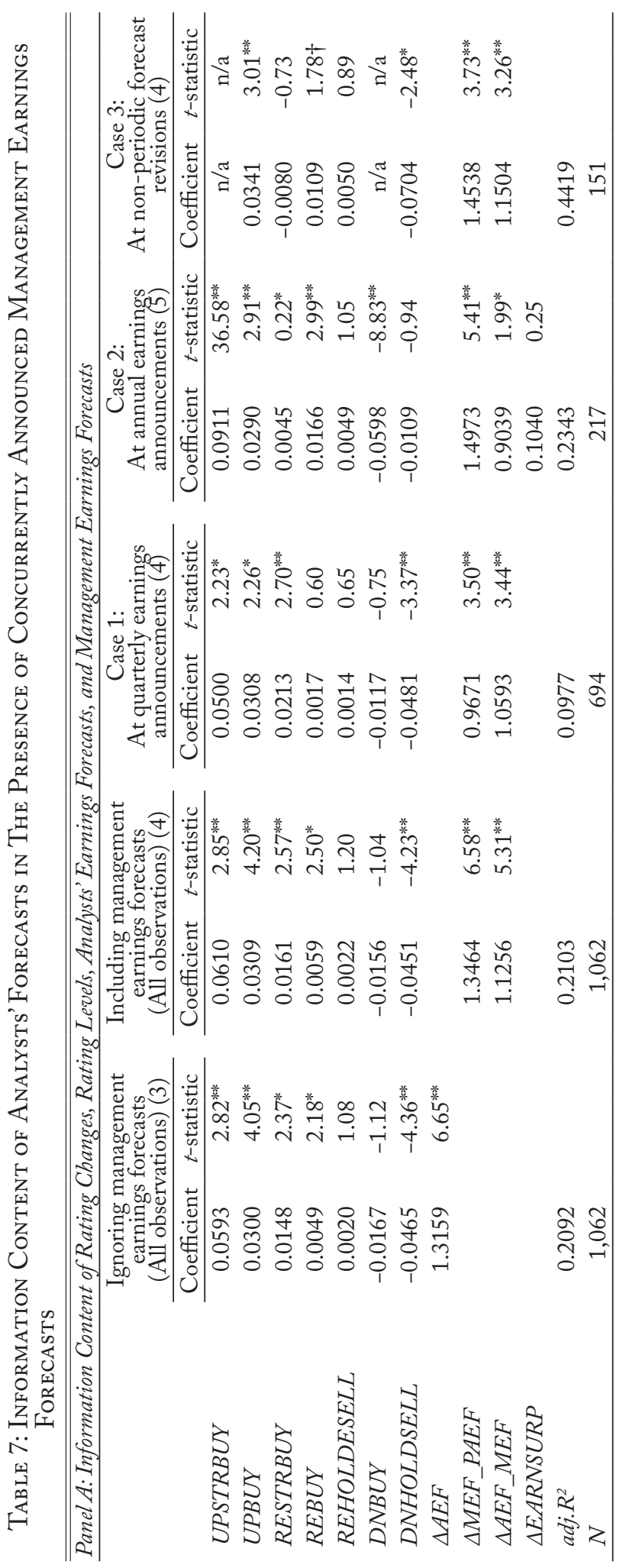

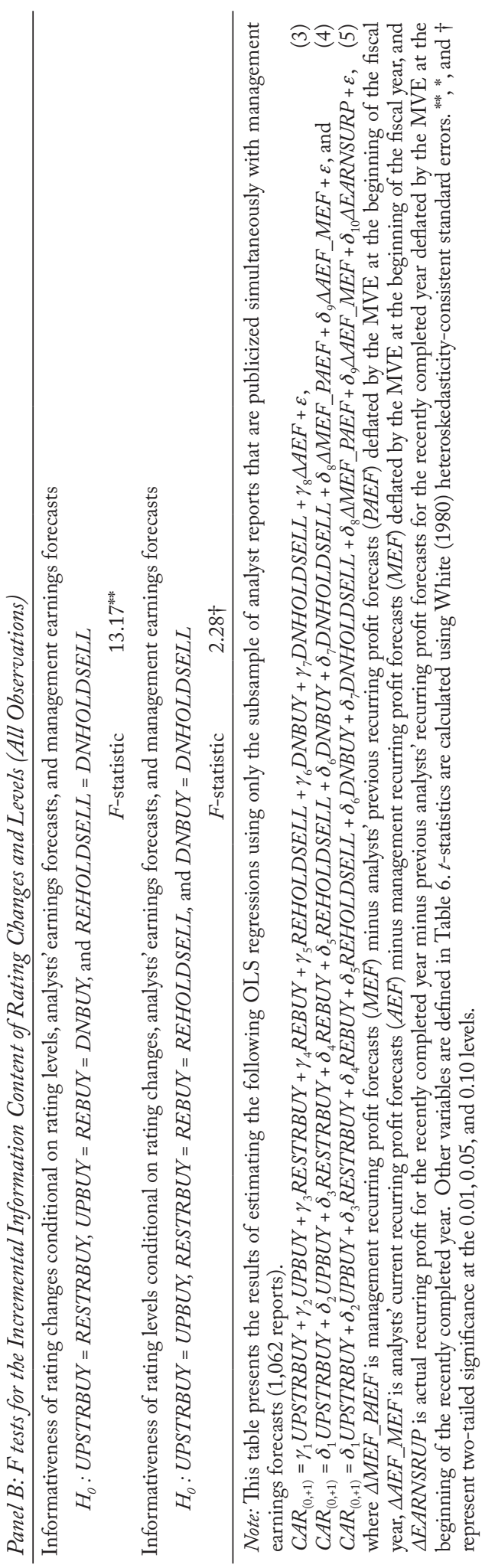


upgrade to strong buy nor downgrade to hold/sell. Thus, the two indicator variables in Eq. (4), UPSTRBUY and DNHOLDSELL, cannot be estimated. As with Cases 1 and 2, the estimated coefficients of $\triangle M E F \_P A E F$ and $\triangle A E F \_M E F$ are both significantly positive, 1.4538 and 1.1504, thereby indicating the incremental information content of management and analysts' earnings forecasts conditional on one another. Case 3 also exhibits the highest adj. $R^{2}$ value, 0.4419 . This may be attributable to the fact that Case 3 provides the most ideal setting for testing the information content of analysts' and management forecasts because no other confounding events take place at non-periodic revisions of management forecasts.

Overall, the results reported in Table 7 indicate that neither companies' earnings forecasts nor concurrently released analysts' earnings forecasts subsume the information of the other. Analysts' stock rating information also possesses incremental information content beyond information provided by the two types of earnings forecasts. These findings suggest that analysts are not merely conveying the information disclosed by managers, but rather are bringing value to the stock market by providing their insights on the firm's future performance. The incremental informativeness of analysts' forecasts in the presence of management forecasts can also be construed as an indication of the stock market relying more on analysts' earnings forecasts than on management earnings forecasts. This possibility is further explored in the next section.

\subsection{Forecast Accuracy of Previous Analysts' Forecasts, Management Forecasts, and Current Analysts' Forecasts}

In this section, I compare the forecast accuracy of previous analysts' forecasts (PAF), management forecasts (MF), and contemporaneously publicized analysts' forecasts (AF) in order to gain insights into the incremental informativeness of AF over MF. Forecast accuracy is measured as the absolute value of the difference between actual and forecasted values deflated by the MVE at the beginning of the fiscal year.

$$
\text { Forecast accuracy }=\left|\frac{\text { Actual value - Forecasted value }}{M V E \text { at the beginning of the fiscal year }}\right| .
$$

All forecasts are one-year-ahead annual forecasts, and the forecasted items that are investigated are sales, operating profit, recurring profit, and net income. The number of observations for each forecasted item differs slightly because managers occasionally disclose forecasts of only certain items.

Table 8 presents the descriptive statistics of the forecast accuracy of PAF, MF, and AF. The average (median) forecast accuracy of PAF, MF, and AF for recurring profit is 0.0169 (0.0080), 0.0145 (0.0069), and $0.0133(0.0055)$, respectively. AF has the smallest average (median) absolute forecast errors followed by MF, and PAF has the largest average (median) absolute forecast errors. Figure 3 depicts the median forecast accuracy of all forecasted items in bar-chart form. The ordering of the forecast accuracy among PAF, MF, and AF remains the same. AF provides the most accurate forecast for all items, followed by MF and PAF.

Panel A of Table 9 presents the results of the paired forecast accuracy tests based on the number of observations. The first, second, and third rows compare the forecast accuracy between PAF and $\mathrm{AF}, \mathrm{PAF}$ and MF, and MF and AF, respectively. For example, when the forecast accuracy of PAF and $\mathrm{MF}$ is compared for recurring profit forecasts in the second row of the third column of Panel A, PAF is more accurate than $\mathrm{MF}$ in $42.1 \%$ of the observations, $\mathrm{PAF}$ is as accurate as $\mathrm{MF}$ in $7.8 \%$ of the observations, and MF is more accurate than PAF in $50.1 \%$ of the observations. The forecast accuracy 
Table 8: Descriptive Statistics of The Forecast Accuracy of Previous Analysts' Forecasts, Management Forecasts, and Current Analysts' Forecasts with Management Forecasts and Current Analysts' Forecasts Being Announced Simultaneously

\begin{tabular}{llccccccc}
\hline \hline & & Average & S.D. & Min & 1Qrt & Median & 3Qrt & Max \\
\hline & SALES & 0.0658 & 0.1000 & 0.0001 & 0.0108 & 0.0307 & 0.0849 & 1.4304 \\
Previous analysts' & OPEPROFIT & 0.0150 & 0.0233 & 0.0000 & 0.0032 & 0.0075 & 0.0183 & 0.2709 \\
forecasts (PAF) & RECURPROFIT & 0.0169 & 0.0278 & 0.0000 & 0.0033 & 0.0080 & 0.0191 & 0.2793 \\
& NETINCOME & 0.0145 & 0.0282 & 0.0000 & 0.0023 & 0.0058 & 0.0152 & 0.3827 \\
\hline \multirow{3}{*}{$\begin{array}{l}\text { Management } \\
\text { forecasts (MF) }\end{array}$} & SALES & 0.0541 & 0.0898 & 0.0000 & 0.0080 & 0.0244 & 0.0638 & 1.1950 \\
& OPEPROFIT & 0.0130 & 0.0215 & 0.0000 & 0.0024 & 0.0064 & 0.0152 & 0.2544 \\
& RECURPROFIT & 0.0145 & 0.0249 & 0.0000 & 0.0024 & 0.0069 & 0.0164 & 0.2546 \\
& NETINCOME & 0.0119 & 0.0259 & 0.0000 & 0.0019 & 0.0049 & 0.0116 & 0.4357 \\
Current analysts' & SALES & 0.0478 & 0.0821 & 0.0000 & 0.0064 & 0.0191 & 0.0558 & 1.1950 \\
forecasts (AF) & OPEPROFIT & 0.0119 & 0.0204 & 0.0000 & 0.0023 & 0.0055 & 0.0134 & 0.2627 \\
& RECURPROFIT & 0.0133 & 0.0241 & 0.0000 & 0.0023 & 0.0055 & 0.0138 & 0.2711 \\
& NETINCOME & 0.0115 & 0.0236 & 0.0000 & 0.0017 & 0.0044 & 0.0107 & 0.2650 \\
\hline
\end{tabular}

Note: This table presents the descriptive statistics of the forecast accuracy of previous analysts' forecasts, management forecasts, and current analysts' forecasts contained in analyst reports that are publicized simultaneously with management forecasts. The forecast accuracy is measured as the absolute value of the difference between actual and forecasted values deflated by the MVE at the beginning of the fiscal year. All forecasts are one-year-ahead annual forecasts and the forecasted items that are investigated are sales (SALES), operating profit (OPEPROFIT), recurring profit (RECURPROFIT), and net income (NETINCOME).

Figure 3: Forecast Accuracy of PAF, MF, and AF.

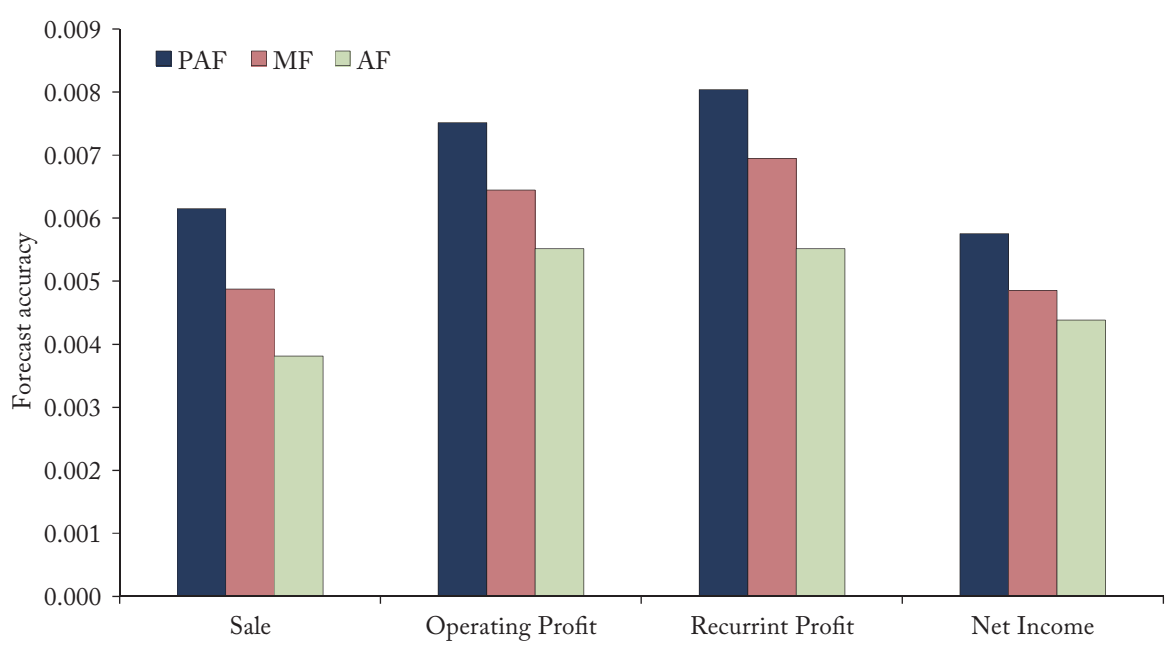

Median forecast accuracy of PAF, MF, and AF

Note: This figure depicts the median forecast accuracy of previous analysts' forecasts (PAF), management forecasts (MF), and current analysts' forecasts (AF) contained in analyst reports that are publicized simultaneously with management forecasts. The forecast accuracy is measured as the absolute value of the difference between actual and forecasted values deflated by the MVE at the beginning of the fiscal year. All forecasts are one-year-ahead annual forecasts and the forecasted items that are investigated are sales $(S A L E S)$, operating profit (OPEPROFIT), recurring profit (RECURPROFIT), and net income (NETINCOME). Note that the median sales forecast accuracy is scaled by one-fifth to make it comparable to others. 

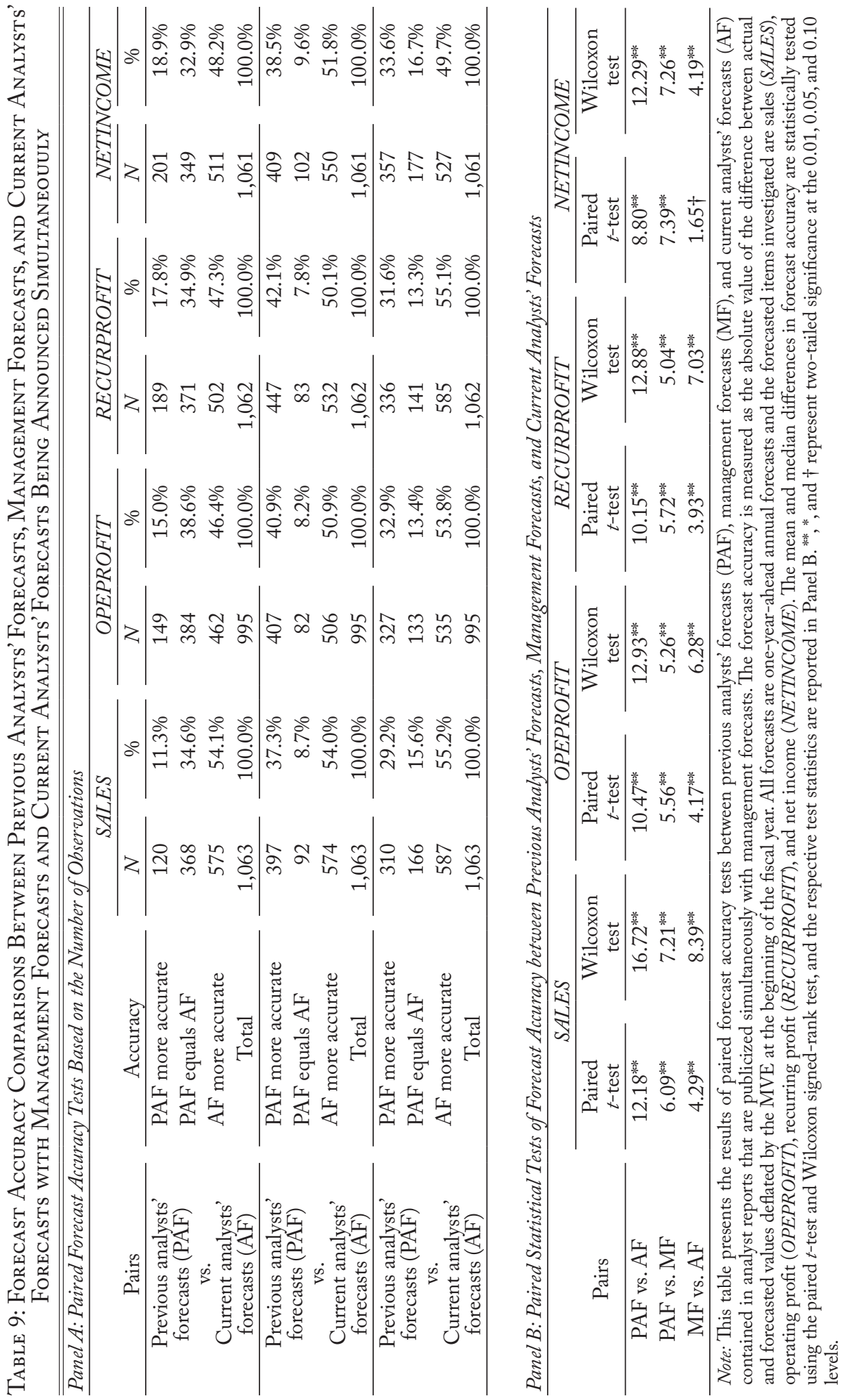
test between MF and AF for recurring profit forecasts in the third row of the third column of Panel A reveals that $\mathrm{MF}$ is more accurate than $\mathrm{AF}$ in $31.6 \%$ of the observations, $\mathrm{MF}$ is as accurate as $\mathrm{AF}$ in $13.3 \%$ of the observations, and $\mathrm{AF}$ is more accurate than $\mathrm{MF}$ in $55.1 \%$ of the observations. The results of other forecasted items are similar to those of recurring profit forecasts.

The mean and median differences in forecast accuracy between PAF and AF, PAF and MF, and MF and AF are statistically tested using the paired $t$-test and Wilcoxon signed-rank test, and the results are reported in Panel B of Table 9. The results of both statistical tests indicate that AF is significantly more accurate than PAF, MF is significantly more accurate than PAF, and AF is significantly more accurate than MF for all forecasted items at the $1 \%$ level except for the mean difference between $\mathrm{MF}$ and $\mathrm{AF}$ for net income, which is statistically significant only at the $10 \%$ level.

Overall, the results presented in Table 9 reveal that management forecasts are more accurate than previous analysts' forecasts but less accurate than concurrently released analysts' forecasts. The superiority of current analysts' forecasts over management forecasts in terms of forecast accuracy may explain the stock market's greater reliance on current analysts' forecasts over management forecasts.

\section{Additional Analysis}

\subsection{The Impact of Ex Post Forecast Accuracy on the Information Content of Analysts' Earnings Forecasts}

The findings in the previous sections show that current analysts' earnings forecasts are informative to the market and significantly more accurate than concurrently announced management earnings forecasts. This raises the question of whether the stock market reacts to current analysts' earnings forecasts unconditionally, even when analysts' forecasts are ex post less accurate than management forecasts.

In order to answer this question, I use two subsamples of analyst reports in which current analysts' earnings forecasts are (i) ex post more accurate than management earnings forecasts and (ii) ex post less accurate than management earnings forecasts. The results of re-estimating Eq. (4) with the two subsamples are reported in Table 10 .

The first column of Table 10 shows the estimated results of Eq. (4) using all observations. The second and third columns of Table 10 present the estimated results for subsamples (i) and (ii), respectively. The estimated coefficients of $\triangle M E F \_P A E F$ are both significantly positive: 1.1320 for the subsample (i) and 0.9890 for the subsample (ii). However, while the estimated coefficient of $\triangle A E F_{-}$ $M E F$ for subsample (i) is significantly positive, 1.1263 ( $t$-statistic $=4.93)$, the estimated coefficient for subsample (ii) is not statistically significant, 0.4773 ( $t$-statistic $=1.00)$. These findings indicate that the market responds to analysts' earnings forecasts only when they provide better forecasts than corporate managers. It appears that the stock market is able to discern the relative ex post forecast accuracy of analysts' earnings forecasts and reacts only to those forecasts that are ex post more accurate than management forecasts.

\subsection{The Impact of Other Firm-Specific Factors}

Prior literature has identified a number of factors associated with the market reaction to the release of analysts' stock ratings and earnings forecasts. First, firm size and the number of analysts following a firm are often used as proxies for the amount of pre-disclosure information available for a firm (Atiase, 1985; Stickel, 1995; Asquith et al., 2005). Since less information is likely to be available to investors about smaller or less widely-followed firms, the market reaction to the release 
Table 10: The Impact of Ex Post Forecast Accuracy on The Information Content of Analysts' and Management Earnings Forecasts

\begin{tabular}{|c|c|c|c|c|c|c|}
\hline & \multicolumn{2}{|c|}{ All observations } & \multicolumn{2}{|c|}{$\begin{array}{c}\text { (i) } A E F \text { more accurate } \\
\text { than } M E F\end{array}$} & \multicolumn{2}{|c|}{$\begin{array}{l}\text { (ii) } A E F \text { less accurate } \\
\text { than } M E F\end{array}$} \\
\hline & Coefficient & $t$-statistic & Coefficient & $t$-statistic & Coefficient & $t$-statistic \\
\hline UPSTRBUY & 0.0610 & $2.85^{* *}$ & 0.0474 & $2.01^{*}$ & 0.0942 & $49.71^{*}$ \\
\hline$U P B U Y$ & 0.0309 & $4.20^{* *}$ & 0.0323 & $4.01^{* *}$ & 0.0464 & $3.17^{\text {** }}$ \\
\hline RESTRBUY & 0.0161 & $2.57^{* *}$ & 0.0146 & 1.68 & 0.0186 & 1.96 \\
\hline$R E B U Y$ & 0.0059 & $2.50^{*}$ & 0.0079 & $2.70^{* *}$ & 0.0031 & 0.71 \\
\hline REHOLDESELL & 0.0022 & 1.20 & 0.0043 & 1.76 & 0.0008 & 0.23 \\
\hline$D N B U Y$ & -0.0156 & -1.04 & 0.0146 & 1.57 & -0.0442 & -1.87 \\
\hline DNHOLDSELL & -0.0451 & $-4.23^{* *}$ & -0.0608 & $-4.02^{* *}$ & -0.0483 & $-2.21^{*}$ \\
\hline$\triangle M E F \_P A E F$ & 1.3464 & $6.58^{* *}$ & 1.1320 & $4.32^{* *}$ & 0.9890 & $2.77^{* *}$ \\
\hline$\triangle A E F \_M E F$ & 1.1256 & $5.31^{* *}$ & 1.1263 & $4.93^{* *}$ & 0.4773 & 1.00 \\
\hline $\operatorname{adj} . R^{2}$ & 0.2103 & & 0.1762 & & 0.1416 & \\
\hline$N$ & 1,062 & & 585 & & 336 & \\
\hline
\end{tabular}

Note: This table examines the impact of the relative ex post forecast accuracy between current analysts' earnings forecasts $(A E F)$ and management earnings forecasts $(M E F)$ on the incremental information content of these earnings forecasts. The following regression model is estimated using only the subsample of analyst reports that are publicized concurrently with management forecasts.

$C A R_{(0,+1)}=\delta_{1} U P S T R B U Y+\delta_{2} U P B U Y+\delta_{3} R E S T R B U Y+\delta_{4} R E B U Y+\delta_{5} R E H O L D S E L L+\delta_{6} D N B U Y+$ $\delta_{7} D N H O L D S E L L+\delta_{8} \triangle M E F \_P A E F+\delta_{9} \triangle A E F \_M E F+\varepsilon$,

where $C A R_{(0,+1)}$ is the cumulative abnormal stock return (raw return minus the market model predicted return) over a two day window comprising the day of the analyst report release and the following trading day, UPSTRBUY is an indicator variable taking the value of one if analysts' ratings are upgraded to strong buy and zero otherwise, $U P B U Y$ is an indicator variable taking the value of one if analysts' ratings are upgraded to buy and zero otherwise, RESTRBUY is an indicator variable taking the value of one if analysts' ratings are unchanged from strong buy and zero otherwise, $R E B U Y$ is an indicator variable taking the value of one if analysts' ratings are unchanged from buy and zero otherwise, REHOLDSELL is an indicator variable taking the value of one if analysts' ratings are unchanged from hold or sell and zero otherwise, $D N B U Y$ is an indicator variable taking the value of one if analysts' ratings are downgraded to buy and zero otherwise, DNHOLDSELL is an indicator variable taking the value of one if analysts' ratings are downgraded to hold or sell and zero otherwise, $\triangle M E F \_P A E F$ is management recurring profit forecasts $(M E F)$ minus analysts' previous recurring profit forecasts $(P A E F)$ deflated by the MVE at the beginning of the fiscal year, and $\triangle A E F \_M E F$ is analysts' current recurring profit forecasts $(A E F)$ minus management recurring profit forecasts $(M E F)$ deflated by the MVE at the beginning of the fiscal year. All earnings forecasts are one-year-ahead annual forecasts. $t$-statistics are calculated using White (1980) heteroskedasticity-consistent standard errors. ${ }^{* * *}$ and * represent two-tailed significance at the 0.01 and 0.05 levels.

of analysts' ratings and earnings forecasts is expected to be greater in magnitude for these firms than for larger or more widely-followed firms. Second, Michaely and Womack (1999) document that the mean excess returns around buy recommendations are lower when the recommendations are made by underwriters rather than by non-underwriters, thereby suggesting that the market discounts the value of underwriter buy recommendations compared to those of non-underwriters. Third, analysts with better reputations are expected to have more influence than others on the stock market. Stickel (1995) finds that rating upgrades (downgrades) from first-team All-American analysts trigger an incremental price increase (decrease) of $1.18 \%(-0.79 \%)$ beyond that associated with non-AllAmericans. Fourth, Skinner and Sloan (2002) document that growth firms with high market-tobook ratios exhibit an asymmetrically large negative price response to negative surprises of actual 
earnings. Asquith et al. (2005) also report similar results for rating downgrade announcements.

Thus, on the basis of the findings in prior studies, I investigate the impact of five firm-specific factors-firm size, analyst following, analyst reputation, underwriting relationship, and firm growth-on market reaction to the simultaneous releases of management earnings forecasts and analysts' rating and earnings forecasts. One problem associated with this test is that the sample must be divided into good and bad news because the signs of estimated coefficients of certain factors are predicted to vary depending on the content of the news. For example, while the sign of the estimated coefficient of firm size is expected to be negative for good news, the opposite sign is predicted for bad news. Concurrent announcements of management and analysts' forecasts make it more difficult to distinguish whether the announcements contain good or bad news overall. Therefore, I divide the sample by the sign of $C A R$, which means that if an announcement is associated with a positive (negative) $C A R$, it is considered to be good (bad) news.

I estimate a version of Eq. (4) modified to include proxies for firm size, analyst following, analyst reputation, underwriting relationship, and firm growth.

$$
\begin{aligned}
C A R_{(0,+1)}= & \delta_{1} U P S T R B U Y+\delta_{2} U P B U Y+\delta_{3} R E S T R B U Y+\delta_{4} R E B U Y+\delta_{5} R E H O L D S E L L+ \\
& \delta_{6} D N B U Y+\delta_{7} D N H O L D S E L L+\delta_{8} \Delta M E F \_P A E F+\delta_{9} \triangle A E F \_M E F+\delta_{10} S I Z E+ \\
& \delta_{11} N U M A N A L+\delta_{12} S T A R+\delta_{13} U N D W R I T E+\delta_{14} B M R+\varepsilon,
\end{aligned}
$$

where $S I Z E$ is the log of market value of equity, NUMANAL is the number of analysts following the firm as reported by IFIS Consensus Data, STAR is an indicator variable taking the value of one if the analyst is chosen as the top analyst at least once in the Nikkei Veritas analyst rankings during the 2005-2007 period and zero otherwise, UNDWRITE is an indicator variable taking the value of one if the brokerage house is the lead managing underwriter of the firm and zero otherwise, and $B M R$ is the firm's book-to-market ratio. The definitions of other variables are the same as those in Eq. (4).

The first and second columns of Table 11 present the results of estimating Eq. (6) on the good news and bad news subsamples, respectively. The results indicate that although the signs of the estimated coefficients of these firm-specific variables are generally consistent with the expected signs, their statistical significance is weak. The only significant variables are STAR for the good news subsample and NUMANAL and BMR for the bad news subsample. These findings suggest that analysts with better reputations have a more positive impact on the market in the case of good news, and that the market reaction is less negative for more widely-followed firms and more negative for higher growth firms in the case of bad news.

With regard to analyst report variables, the noteworthy results from Table 7 still hold. The estimated coefficients of $\triangle M E F \_P A E F$ and $\triangle A E F \_M E F$ are positive and significant for both subsamples; this indicates that the information content of management and analysts' earnings forecasts remains intact after controlling for the impact of other firm-specific factors.

\section{Conclusion}

The literature on financial analysts asserts that there are two main sources of value that analysts bring to the market (Park and Pincus, 2000; Ivković and Jegadeesh, 2004). First, analysts' value may lie in their skills to interpret public signals through their expertise. Second, analysts' service may lie in their ability to acquire private signals through their independent research. While analysts' roles as acquirers of new 
Table 11: The Impact of Other Firm-Specific Factors on The Information Content of Analysts' and Management Earnings Forecasts

\begin{tabular}{|c|c|c|c|c|c|c|}
\hline & \multicolumn{3}{|c|}{ Good News (Positive $C A R$ ) } & \multicolumn{3}{|c|}{ Bad News (Negative $C A R$ ) } \\
\hline & Expected Sign & Coefficient & $t$-statistic & Expected Sign & Coefficient & $t$-statistic \\
\hline UPSTRBUY & + & 0.0638 & $2.89^{* *}$ & + & $\mathrm{n} / \mathrm{a}$ & \\
\hline$U P B U Y$ & + & 0.0384 & $2.36^{* *}$ & + & $\mathrm{n} / \mathrm{a}$ & \\
\hline RESTRBUY & ? & 0.0426 & $2.61^{* *}$ & ? & -0.0559 & $-3.17^{* *}$ \\
\hline REBUY & ? & 0.0281 & $1.78^{*}$ & ? & -0.0522 & $-3.24^{* *}$ \\
\hline REHOLDESELL & ? & 0.0249 & $1.68^{*}$ & ? & -0.0587 & $-3.63^{* *}$ \\
\hline$D N B U Y$ & - & $\mathrm{n} / \mathrm{a}$ & & - & -0.0729 & $-3.40^{* *}$ \\
\hline DNHOLDSELL & - & $\mathrm{n} / \mathrm{a}$ & & - & -0.0968 & $-4.95^{* *}$ \\
\hline$\triangle M E F \_P A E F$ & + & 0.7453 & $3.34^{* *}$ & + & 0.9507 & $3.74^{* *}$ \\
\hline$\triangle A E F \_M E F$ & + & 0.9960 & $3.60^{* *}$ & + & 0.6201 & $2.57^{* *}$ \\
\hline$S I Z E$ & - & 0.0004 & 0.32 & + & 0.0006 & 0.46 \\
\hline NUMANAL & - & -0.0005 & -1.30 & + & 0.0007 & $1.66^{*}$ \\
\hline STAR & + & 0.0021 & $2.70^{* *}$ & - & -0.0038 & -0.70 \\
\hline UNDWRITE & - & 0.0084 & 1.64 & - & -0.0061 & -1.34 \\
\hline$B M R$ & ? & 0.0025 & 0.50 & + & 0.0225 & $3.63^{* *}$ \\
\hline $\operatorname{adj} . R^{2}$ & & 0.0961 & & & 0.2685 & \\
\hline$N$ & & 557 & & & 505 & \\
\hline
\end{tabular}

Note: This table examines the impact of other firm-specific factors on the incremental information content of analysts' and management earnings forecasts. The following regression model is estimated using only the subsample of analyst reports that are publicized concurrently with management forecasts.

$C A R_{(0,+1)}=\delta_{1} U P S T R B U Y+\delta_{2} U P B U Y+\delta_{3} R E S T R B U Y+\delta_{4} R E B U Y+\delta_{5} R E H O L D S E L L+\delta_{6} D N B U Y+$

$\delta_{7} D N H O L D S E L L+\delta_{8} \triangle M E F \_P A E F+\delta_{9} \triangle A E F \_M E F+\delta_{10} S I Z E+\delta_{11} N U M A N A L+\delta_{12} S T A R+$

$\delta_{13} U N D W R I T E+\delta_{14} B M R+\varepsilon$,

where $S I Z E$ is the log of market value of equity, NUMANAL is the number of analysts following the firm as reported by IFIS Consensus Data, STAR is an indicator variable taking the value of one if the analyst is chosen as the top analyst at least once in the Nikkei Veritas analyst rankings during the 2005-2007 period and zero otherwise, UNDWRITE is an indicator variable taking the value of one if the brokerage house is the lead managing underwriter of the firm and zero otherwise, and $B M R$ is the firm's book-to-market ratio. Other variables are defined in Table 10. $t$-statistics are calculated using White (1980) heteroskedasticity-consistent standard errors. ${ }^{* *}$ and * represent one-tailed significance at the 0.01 and 0.05 levels.

information through their own research are well documented in the literature, their roles as interpreters of public information have not been thoroughly explored thus far (Asquith et al., 2005).

The primary goal of this paper is to investigate whether analysts possess valuable expertise for interpreting public information. Toward this goal, I examine the incremental informativeness of analyst reports released contemporaneously with companies' earnings forecasts, which is probably one of the most important sources of public information. Using 2,277 analyst reports published during the two-year period from July 2005 through June 2007 covering 399 firms, I first replicate prior research and find that both analysts' ratings and earnings forecast revisions are informative to the market. Next, I examine the timing of the publication of analyst reports relative to the announcement of companies' earnings forecasts. I find that over half of the analyst reports (1,062 reports) are issued on the day after the announcement of management earnings forecasts. Since the vast majority of companies announce earnings forecasts after the market closes for the day and analysts disseminate 
the reports for their clients before the market opens the next morning, these analyst reports are practically released contemporaneously with management forecasts.

Thereafter, I investigate the information content of analysts' ratings and earnings forecasts using only the subsample of analyst reports that occur with management earnings forecasts. I find that analysts' ratings and earnings forecasts have incremental information content beyond information provided by management forecasts. Controlling for the impact of actual earnings at annual earnings announcements does not materially change the results.

The results of the incremental informativeness of analysts' forecasts in the presence of management forecasts indicate that the market relies more on analysts' forecasts than on management forecasts. When the ex post forecast accuracy of management earnings forecasts and concurrently released analysts' earnings forecasts is compared, the results show that analysts' forecasts are significantly more accurate than management forecasts. This finding may partially explain why investors depend more on analysts' outlooks than on corporate managers' views of future earnings.

In summary, this paper presents strong evidence that the stock market reacts to forecast information contained in an analyst report beyond forecast information that is publicly disseminated by companies' managers. The stock market's reaction may be justified by the ex post higher accuracy of analysts' earnings forecasts than simultaneously announced management earnings forecasts. These findings indicate that security analysts are not merely reiterating publicly announced information, but are adding value to the market by providing new analysis and assessment of companies' future performance.

\section{REFERENCES}

ABDel-KhaliK, R., AND B. AJINKYA. 1982. Returns to informational advantages: The case of analysts' forecast revisions. The Accounting Review 57 (October): 661-680.

Asquith, P., M. MikHAil, AND A. AU. 2005. Information content of equity analyst reports. Journal of Financial Economics 75 (February): 245-282.

ATIASE, R. 1985. Predisclosure information, firm capitalization, and security price behavior around earnings announcements. Journal of Accounting Research 23 (Spring): 21-36.

Barber, B., R. Lehavy, M. McNichols, And B. Trueman. 2001. Can investors profit from the prophets? Security analyst recommendations and stock returns. The Journal of Finance 56 (Spring): 531-563.

Bowen, R., A. Davis, And D. Matsumoto. 2002. Do conference calls affect analysts' forecasts? The Accounting Review 77 (April): 285-316.

BRAV, A., AND R. LEHAVY, 2003. An empirical analysis of analysts' target prices: short-term informativeness and long-term dynamics. The Journal of Finance 58 (October): 1933-1967.

Campbell, J., A. Lo, And C. MacKinlay. 1996. The Econometrics of Financial Markets. Princeton University Press, Princeton, NJ.

CONROY, R., K. EADES, AND R. HARRIS. 2000. A test of the relative pricing effects of dividends and earnings: Evidence from simultaneous announcements in Japan. The Journal of Finance 55 (June): 1199-1227.

CONROY, R., R. HARRIS, AND Y. PARK. 1998. Fundamental information and share prices in Japan: Evidence from earnings surprises and management predictions. International Journal of Forecasting 14 (June): 227-244.

Elton, E., M. Gruber, And S. Grossman. 1986. Discrete expectational data and portfolio performance. The Journal of Finance 41 (July): 699-713.

FRANCIS, J., AND L. SOFFER. 1997. The relative informativeness of analysts' stock recommendations and earnings forecast revisions. Journal of Accounting Research 35 (Autumn): 193-211.

IVković, Z., AND N. JegAdEESH. 2004. The timing and value of forecast and recommendation revisions. Journal of Financial Economics 73 (September): 433-463.

LYS, T., AND S. SOHN. 1990. The association between revisions of financial analysts' earnings forecasts and security-price changes. Journal of Accounting and Economics 13 (December): 341-363.

MACKINLAY, C. 1997. Event studies in economics and finance. Journal of Economic Literature 35 (March): 13-39.

Michaely, R., AND K. WOMACK. 1999. Conflict of interest and the credibility of underwriter analyst recommendations. The Review of Financial Studies 12: 653-686.

OTA, K. 2010. The value relevance of management forecasts and their impact on analysts' forecasts: Empirical evidence from Japan. 
Abacus 46 (March): 28-59.

PARK, C., AND M. PiNCUS. 2000. Market reactions to changes in analyst consensus recommendations following quarterly earnings announcements. Unpublished Working Paper, Hong Kong University of Science and Technology.

SKINNER, D., AND R. SLOAN. 2002. Earnings surprises, growth expectations, and stock returns or don't let an earnings torpedo sink your portfolio. Review of Accounting Studies 7 (June): 289-312.

STICKEL, S. 1989. The timing of and incentives for annual earnings forecasts near interim earnings announcements. Journal of Accounting and Economics 11 (Special Issue) (July): 275-292.

STICKEL, S. 1991. Common stock returns surrounding earnings forecast revisions: More puzzling evidence. The Accounting Review 66 (April): 402-416.

STICKEL, S. 1995. The anatomy of the performance of buy and sell recommendations. Financial Analysts Journal 51 (SeptemberOctober): 25-39.

WHITE, H. 1980. A heteroskedasticity-consistent covariance matrix estimator and a direct test for heteroskedasticity. Econometrica 48 (May): 817-838.

WOMACK, K. 1996. Do brokerage analysts' recommendations have investment value? The Journal of Finance 51 (March): 137-167. 